\title{
Cerebellar Climbing Fibers Modulate Simple Spikes in Purkinje Cells
}

\author{
Neal H. Barmack and Vadim Yakhnitsa \\ Neurological Sciences Institute, Oregon Health and Science University, Beaverton, Oregon 97006
}

Purkinje cells have two action potentials: Climbing fiber responses (CFRs) and simple spikes (SSs). CFRs reflect the discharge of a single climbing fiber at multiple synaptic sites on the proximal dendrite of the Purkinje cell. SSs reflect the summed action of a subset of parallel fiber synapses on Purkinje cell dendritic spines. Because mossy fiber afferents terminate on granule cells, the ascending axons of which bifurcate, giving rise to parallel fibers, the modulation of SSs has been attributed to mossy fiber afferent signals. This inference has never been tested. Conversely, the low discharge frequency of CFRs has led many to conclude that they have a unique and intermittent role in cerebellar signal processing. We examine the relative potency of vestibularly modulated mossy fiber and climbing fiber signals in evoking CFRs and SSs in Purkinje cells of the uvula-nodulus in chloralose- urethane-anesthetized rabbits. Vestibular primary afferents were blocked by unilateral labyrinthectomy (UL). A UL destroys the vestibular primary afferent signal to the ipsilateral uvula-nodulus, while leaving intact the vestibular climbing fiber signal from the contralateral inferior olive. After UL, vestibular stimulation modulated CFRs and SSs in ipsilateral uvula-nodular Purkinje cells, demonstrating that the primary vestibular afferent mossy fiber input to the ipsilateral uvula-nodulus was not necessary for SS modulation. Unilateral microlesions of the caudal half of the $\beta$-nucleus of the inferior olive reduced a modulated climbing fiber signal to the contralateral uvula-nodulus, causing loss of both vestibularly modulated CFRs and SSs in contralateral Purkinje cells. Vestibular climbing fibers not only evoke low-frequency CFRs, but also indirectly modulate higherfrequency SSs. This modulation must be attributed to cerebellar interneurons. Golgi cell inhibition of granule cells may provide the interneuronal mechanism for CFR-induced SS modulation.

Key words: cerebellum; nodulus; uvula; vestibular primary afferents; parallel fiber; climbing fiber response; Golgi cell

\section{Introduction}

Cerebellar Purkinje cells have two action potentials: Climbing fiber responses (CFRs) and simple spikes (SSs). CFRs are longduration (2-5 msec), multipeaked action potentials that discharge at 1-5 impulses (imp)/sec. They are evoked by the multisynaptic contacts of a single climbing fiber on the proximal dendrite of a Purkinje cell (Granit and Phillips, 1956; Eccles et al., 1966a). SSs have short-duration (0.75-1.25 msec), single-peaked action potentials that discharge at $20-60 \mathrm{imp} / \mathrm{sec}$.

Whereas modulation of CFRs reflects the direct action of a single climbing fiber, modulation of SSs is less well understood. Several synaptic inputs, parallel fibers being the most numerous, converge on Purkinje cells. The net excitability evoked by these inputs modulates SSs. The activity of parallel fibers reflects the excitability of mossy fiber synaptic terminals at glomerular synapses on granule cell dendrites. The other presynaptic component of the glomerular synapse, the Golgi cell inhibitory axon terminal, also modulates the activity of granule cells (Eccles et al., 1966b).

The activity of Purkinje cells of the cerebellar-nodulus is strongly influenced by vestibularly driven climbing fiber inputs. Vestibularly evoked increases in CFRs are associated with de-

\footnotetext{
Received Dec. 27, 2002; revised June 18, 2003; accepted July 8, 2003.

This work was supported by National Eye Institute Grant EY04778 to N.H.B. We thank Mary Westcott for expert histological assistance.

Correspondence should be addressed to Dr. Neal H. Barmack, Neurological Sciences Institute, Oregon Health and Science University, 505 Northwest 185th Avenue, Beaverton, Oregon 97006. E-mail: barmackn@ohsu.edu. Copyright $\odot 2003$ Society for Neuroscience $\quad$ 0270-6474/03/237904-13\$15.00/0
}

creases in SSs (Barmack and Shojaku, 1995; Fushiki and Barmack, 1997). Even during spontaneously occurring CFRs, the duration of this climbing fiber-induced pause lasted 15-300 msec (Granit and Phillips, 1956; Bell and Grimm, 1969). The question arises, could the antiphasic activity of CFRs and SSs be attributed to independent mossy and climbing fiber pathways? Afferent signals in these separate pathways could themselves be antiphasic, resulting in the observed antiphasic behavior of CFRs and SSs. Alternatively, vestibular signals conveyed by climbing fibers could modulate the discharge of SSs indirectly through the action of cerebellar interneurons.

If it were possible to manipulate independently the signals conveyed by climbing and mossy fibers, then their separate and joint contributions to the modulation of SSs could be resolved. Vestibular pathways to the uvula-nodulus offer the possibility for such an experiment. More than $70 \%$ of primary vestibular afferents project to folia $9 \mathrm{~d}$ and 10 in the ipsilateral uvula-nodulus as mossy fibers (Carpenter et al., 1972; Korte, 1979; Kevetter and Perachio, 1986; Barmack et al., 1993a). Vestibular climbing fibers originate from two subnuclei of the inferior olive, the $\beta$-nucleus and dorsomedial cell column ( $\mathrm{dmcc}$ ). They cross the midline to synapse on Purkinje neurons in the contralateral uvula-nodulus (Barmack et al., 1993b; Barmack, 1996; Kaufman et al., 1996) (Fig. 1). The $\beta$-nucleus and dmcc receive secondary vestibular projections from the ipsilateral parasolitary nucleus, a small GABAergic nucleus that receives a primary vestibular afferent projection (Barmack et al., 1998; Barmack and Yakhnitsa, 2000). 


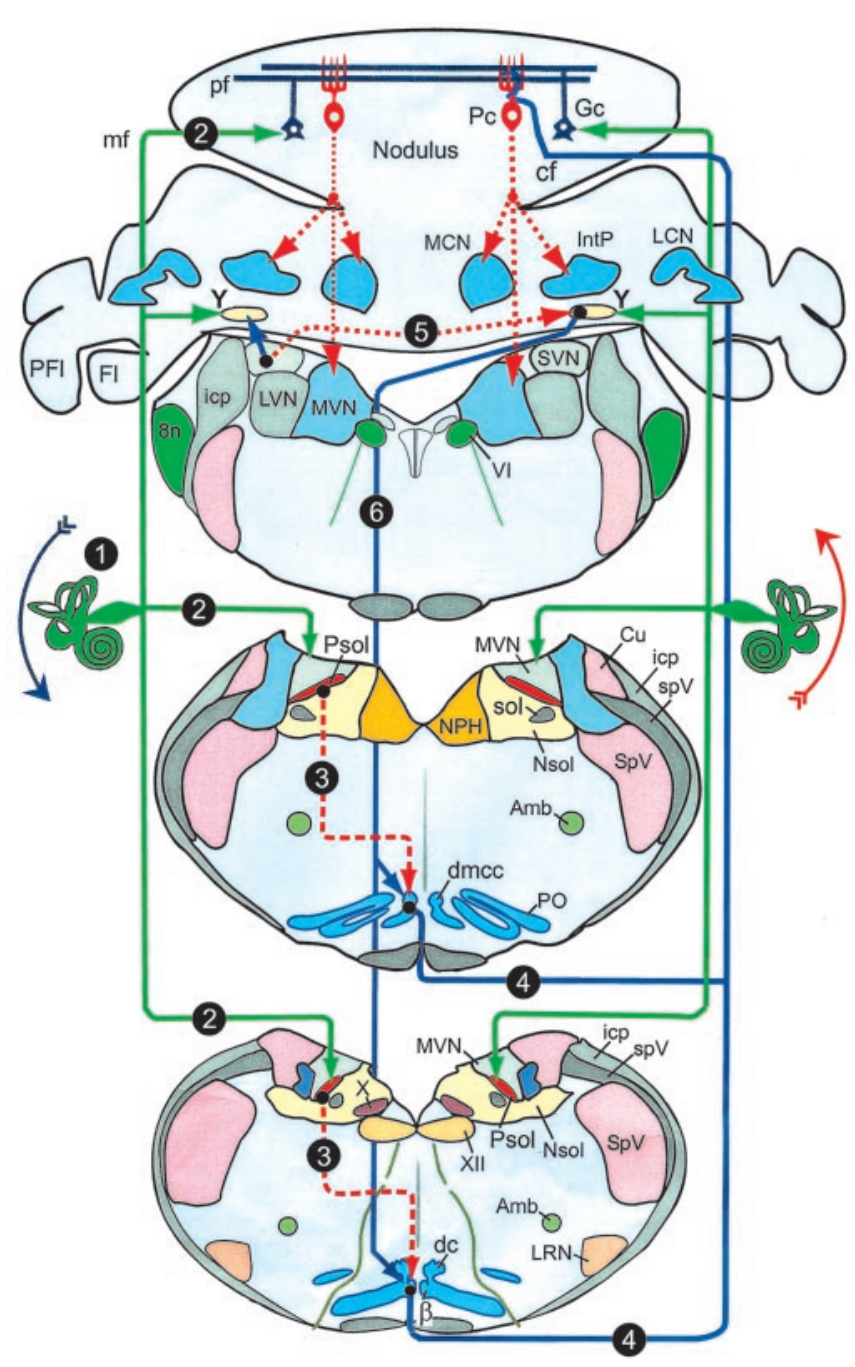

Figure 1. Vestibular primary afferent mossy fiber and climbing fiber projections to uvulanodulus. Sequences in activation are indicated by solid lines for excitatory pathways and dashed lines for inhibitory pathways, listed numerically. 1, Roll-tilt onto the left side increases primary afferent discharge; 2, primary afferent mossy fibers project to ipsilateral Psol, Y-group, and granule cell layer of nodulus; 3 , Psol projects to ipsilateral $\beta$-nucleus and dmcc; 4 , climbing fibers from $\beta$-nucleus and dmcc project to contralateral nodulus; 5 , vestibular nuclei project bilaterally to $\mathrm{Y}$-group; 6 , Y-group projects to contralateral dorsal cap, $\beta$-nucleus, and dmcc; Amb, nucleus ambiguus; $\beta, \beta$-nucleus; cf, climbing fiber; $\mathrm{Cu}$, cuneate nucleus; $\mathrm{dc}$, dorsal cap; DVN, LVN, MVN and SVN, descending, lateral, medial, and superior vestibular nucleus, respectively; Fl, flocculus; Gc, granule cell; icp, inferior cerebellar peduncle; LRN, lateral reticular nucleus; mf, mossy fiber; LCN, MCN and IntP, lateral, medial and interpositus cerebellar nucleus, respectively; NPH, nucleus prepositus hypoglossi; Nsol, nucleus solitarius; Pc, Purkinje neuron; pf, parallel fiber; PFI, paraflocculus; PO, principal olive; Psol, parasolitary nucleus; sol, tractus solitarius; SpV, spinal trigeminal nucleus; $s p V$, spinal trigeminal tract; $X$, dorsal motor nucleus of the vagus; XII, hypoglossal nucleus; $V \mathrm{l}$, abducens nucleus; $Y, Y$-group: $8 \mathrm{n}$, auditory-vestibular nerve.

Vestibular primary afferent signals to the ipsilateral uvulanodulus can be blocked by a unilateral labyrinthectomy (UL), without disrupting vestibular climbing fibers that originate from the contralateral inferior olive. Conversely, vestibular climbing fiber signals can be blocked by unilateral microlesions of the contralateral $\beta$-nucleus, leaving intact signals from ipsilateral vestibular primary afferents. We have blocked separately vestibular primary afferent mossy fiber and climbing fiber pathways to the uvula-nodulus. We have recorded extracellularly from Purkinje cells to assess the contributions of these pathways to the modulation of SSs.

\section{Materials and Methods}

Anesthesia and surgery. Fifteen pigmented rabbits (weight, $0.8-1.7 \mathrm{~kg}$ ) were anesthetized intravenously with $\alpha$-chloralose (50 mg/kg) and urethane $(500 \mathrm{mg} / \mathrm{kg})$ or anesthetized intramuscularly with ketamine hydrochloride $(50 \mathrm{mg} / \mathrm{kg})$, xylazine $(6 \mathrm{mg} / \mathrm{kg})$, and acepromazine maleate $(1.2 \mathrm{mg} / \mathrm{kg})$. Rectal temperature was monitored and maintained at $37^{\circ} \mathrm{C}$. The adequacy of anesthesia was evaluated using the corneal reflex as an indicator.

In a preparatory operation, a dental acrylic plug was formed to the calvarium of each rabbit. This plug held two inverted stainless steel screws (8-32) to the dorsal surface of the calvarium. Five smaller stainless steel screws (2-56) were screwed into the calvarium and helped to anchor the acrylic plug. The larger inverted screws mated with a metal rod that maintained the head rigidly in the center of a three-axis vestibular rate table.

Unilateral labyrinthectomy. The left labyrinth was destroyed surgically in eight rabbits. A retroauricular $5 \mathrm{~mm}$ incision was made to gain access to the middle ear through the tympanic membrane. The stapes was disinserted from the oval window. A fine dental drill was used to open the bony cochlea-labyrinth. The pigmented membranous labyrinth was visualized and removed with a fine forceps. To make certain that the entire vestibular apparatus was damaged, the dental drill was used to excavate the remaining bony labyrinth. Approximately $60 \mathrm{~min}$ after the UL, electrical recording was begun.

Microelectrode recording. The uvula-nodulus was approached by reflecting the muscles overlying the cisterna magna and enlarging the dorsal aspect of the foramen magnum. The outer layers of the dura mater were peeled away exposing folia $9 \mathrm{~b}$ and $9 \mathrm{c}$ through the remaining layer. A microdrive, attached to the head restraint bar, advanced tungsten microelectrodes through folia $9 \mathrm{~b}$ and $9 \mathrm{c}$ toward folia $9 \mathrm{~d}$ and 10 . The microelectrodes had an extended taper so that the diameter of the final $4 \mathrm{~mm}$, the length necessary for a complete penetration of the uvula-nodulus, was $<50 \mu \mathrm{m}$. The tip impedance was $\sim 4 \mathrm{M} \Omega$.

Action potentials were discriminated with a window-slope-Schmitt trigger. Action potentials were analyzed using Spike 2 software (Cambridge Electronic Design) and displayed in peristimulus histograms. CFR-associated pauses in SS activity were analyzed with peri-CFRtriggered SS histograms, in which SSs, time locked to CFRs, were averaged.

Histological verification of recording sites. The location of each recorded neuron was marked electrolytically ( $8 \mu \mathrm{A}, 30 \mathrm{sec}$; electrode negative). At the end of the experiment, rabbits were perfused transcardially with $0.9 \%$ saline, followed by $10 \%$ paraformaldehyde. The brain was removed and cryoprotected with 10, 20, and 30\% sucrose in $0.1 \mathrm{M}$ PBS, pH 7.2. The posterior cerebellum was blocked sagittally, mounted onto cork with optimal cutting temperature compound (OCT; Tissue-Tek), and frozen in isopentane cooled with dry ice. Sagittal frozen sections were cut at $35 \mu \mathrm{m}$.

Vestibular stimulation. The rate table sinusoidally oscillated the prone rabbit about its vertical axis (yaw), longitudinal axis (roll), and interaural axis (pitch) $\left( \pm 10^{\circ} ; 0.005-0.800 \mathrm{~Hz}\right)$. During vestibular stimulation, form vision of the rabbit was occluded by hemispherical ping pong balls.

The peripheral origins of vestibularly modulated signals were characterized using a "null technique." While the rabbit was roll-tilted sinusoidally, the angle of the rabbit's head-body was varied continuously from roll-to-pitch, until a minimal modulated Purkinje cell discharge was observed. On either side of this null plane, the phase of modulated activity shifted by $180^{\circ}$ with respect to the sinusoidal vestibular stimulus. The optimal plane, the plane of maximal modulated discharge, was assumed to be orthogonal to the null plane (Fushiki and Barmack, 1997).

The otolithic origin of vestibularly modulated discharges was tested by static roll-tilt. The rabbit was statically roll-tilted $5-10^{\circ}$ about a previously defined optimal axis. After an adaptation period of 20-30 sec, the average discharge frequency was measured for the next $20-30 \mathrm{sec}$. The rabbit was then roll-tilted in the opposite direction. A difference in mean discharge frequency of $>40 \%$, evoked for static tilts in the two opposite directions, indicated static responsiveness to linear acceleration.

Optokinetic stimulation. The vestibular rate table was located within a sphere having a diameter of $135 \mathrm{~cm}$. A $20 \mathrm{~W}$ halogen light bulb with a rectangular filament was mounted at the center of a perforated alumi- 

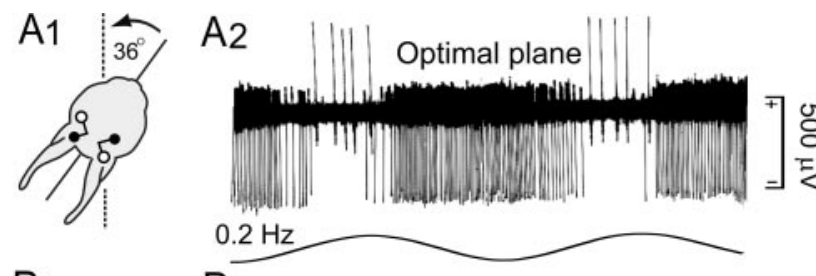

$\mathrm{D}$

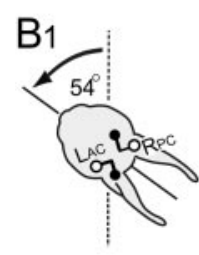

B2 Null plane

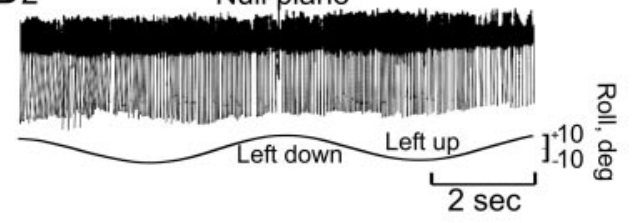

C
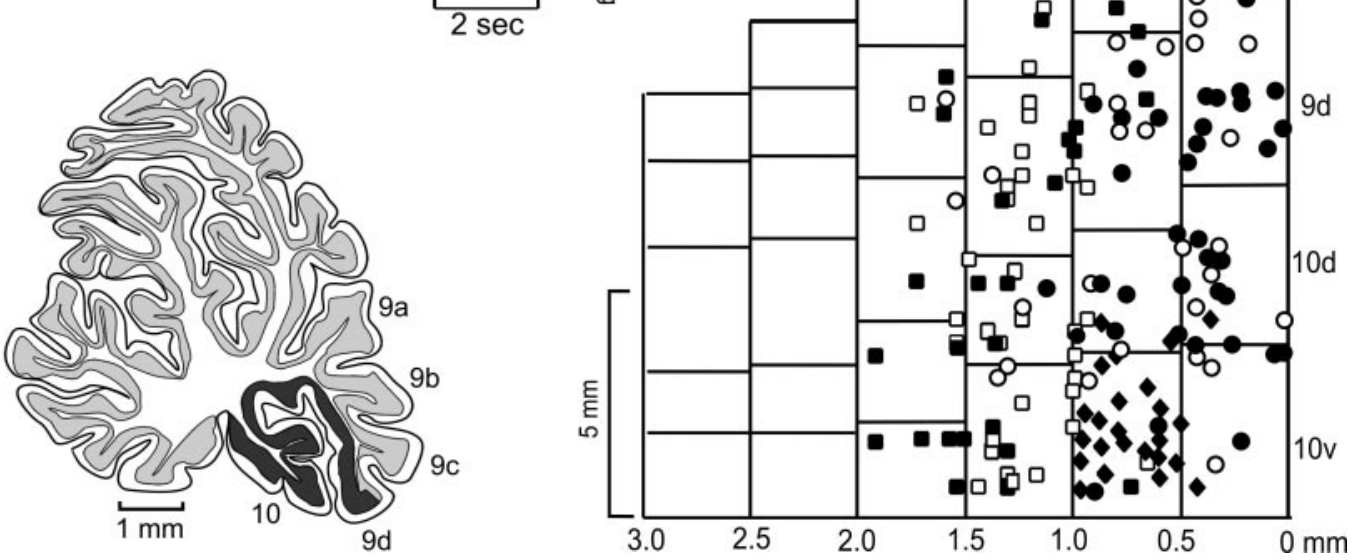

Figure 2. Topographic distribution of CFR optimal planes within uvula-nodulus. Sinusoidal vestibular stimulation was used to classify optimal response planes of CFRs. $A, B$, Figurines illustrate optimal $\left(A_{7}\right)$ and null $\left(B_{7}\right)$ CFR response planes of a Purkinje cell recorded in the left uvula. Stimulation in the optimal plane $\left(A_{2}\right)$ evoked increased CFRs and decreased SSs when the rabbit was rotated onto its left side. When stimulated in the null plane $\left(B_{2}\right)$, neither CFRs nor SSs were modulated. C, Sagittal view of the rabbit cerebellum. The shaded area (folia $9 \mathrm{~d}$ and 10$)$ indicates the region of the uvula-nodulus receiving vestibular primary afferent projection. D, Folia $9-10$ are represented as a two-dimensional topographic sheet. Optimal planes for CFRs recorded from 205 Purkinje cells are represented on this surface. Cells with optimal planes corresponding to stimulation in the plane of the ipsilateral posterior semicircular canal ( $L_{\mathrm{pC}}$ ) are illustrated as circles. Cells with optimal planes corresponding to stimulation in the plane of the ipsilateral anterior semicircular canal $\left(\mathrm{L}_{\mathrm{AC}}\right)$ are illustrated as squares. Open symbols indicate cells in which the optimal plane was determined only for sinusoidal stimulation. Filled symbols indicate cells that were tested for static sensitivity and were positive. Black diamonds indicate cells that responded only to horizontal optokinetic stimulation $\left(\mathrm{L}_{\text {HоK }}\right)$ of the ipsilateral eye in the posterior-anterior direction. The more lateral aspects of folia $9-10$ were unexplored.

num globe, $4.4 \mathrm{~cm}$ in diameter. The globe was attached to the shaft of a gimbal-mounted galvanometer directly above the head of the rabbit (Leonard et al., 1988). The globe projected rectangular images $\left(3 \times 8^{\circ}\right)$ of the filament on the interior surface of the large sphere. These images were spaced $15^{\circ}$ apart, with the long axis orthogonal to the plane of rotation. The maximal intensity $\left(I_{\mathrm{Max}}\right)$ of the image was measured with a spot photometer that had a $0.5 \mathrm{~mm}$ slit opening. The minimal intensity $\left(I_{\mathrm{Min}}\right)$ was measured from the space in between the projected rectangular images. The contrast $(\mathrm{K})$ of the projected images was: $\mathrm{K}=\left(I_{\mathrm{Max}}-I_{\mathrm{Min}}\right) /$ $\left(I_{\text {Max }}+I_{\text {Min }}\right)=0.48$. For horizontal optokinetic stimulation (OKS), the rotational axis of the gimbal-mounted globe was aligned with the vertical axis. For vertical OKS, it was aligned with the longitudinal axis or one of the axes of the vertical semicircular canals. Sinusoidal, monocular OKS had a constant amplitude $\left( \pm 10^{\circ}\right)$ over a frequency range of $0.005-0.200 \mathrm{~Hz}$.

\section{Results}

Vestibularly evoked CFRs and SSs within uvula-nodular zones

The CFRs of $>90 \%$ of the Purkinje cells recorded in folia $9 \mathrm{c}, \mathrm{d}$ and 10 were modulated by sinusoidal and static roll-tilt. Ipsilateral roll increased CFRs and decreased SSs (Fig. $2 A-C$ ). The rotational angle of the head with respect to the vertical axis was changed systematically to determine the angle at which roll-pitch stimulation caused no modulation of CFRs or SSs; the null plane (Fig. $2 B_{1,2}$ ). The optimal plane was orthogonal to the null plane (Fig. $2 A_{1,2}$ ). Optimal planes of most Purkinje cells were aligned with bilateral pairs of vertical semicircular canals, ipsilateral posterior-contralateral anterior or ipsilateral anterior-contralateral posterior semicircular canals. Optimal CFR planes aligned with the ipsilateral posterior-contralateral anterior semicircular canals were distributed in a medial sagittal zone extending from the midline to $\sim 1.2 \mathrm{~mm}$ lateral to the midline. Optimal CFR planes aligned with the ipsilateral anterior-contralateral posterior semicircular canals were distributed in a more lateral sagittal zone starting at $\sim 1 \mathrm{~mm}$ and extending to $2.2 \mathrm{~mm}$ lateral of the midline (Fig. 2D). Although modulation of CFRs was observed in folia $9 \mathrm{a}, \mathrm{b}$, the distinction between zonal alignments was obscured. In $10 \%$ of the cells within the two zones, CFRs and SSs were unresponsive to vestibular stimulation. The alignment of CFR zones corresponding to the orientation of vertical semicircular canals was not altered by a UL.

\section{Modulated SSs persist in the ipsilateral uvula-nodulus after UL}

If modulation of SSs were dependent on intact ipsilateral vestibular primary afferents, then it should be abolished by the destruction of these afferents. After a UL, modulation of SSs and CFRs in ipsilateral Purkinje cells persisted (Fig. 3). CFRs increased and SSs decreased when the rabbit was rolled onto the side ipsilateral to the UL.

The antiphasic interaction of CFRs and SSs was evident in peristimulus histograms (Fig. 3B-D). Each cycle of vestibular stimulation was divided into 180 bins. Two separate sets of bins were kept for SSs and CFRs. Interspike intervals were summed in 
A

$1.7 \mathrm{~mm}$ left of midline

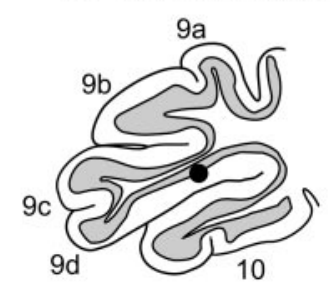

C

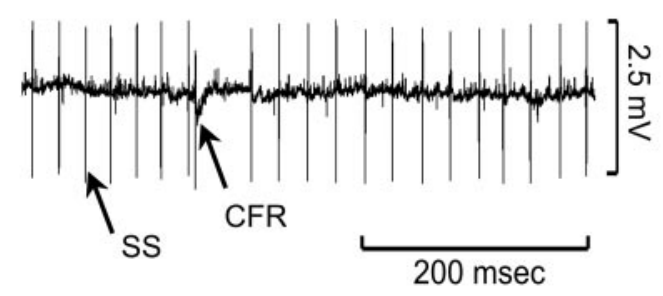

$E$

Mean rate $=1 /\left(\sum\right.$ interspike intervals in bin $) /($ spike count in bin $)$ $\mathrm{N}=15$

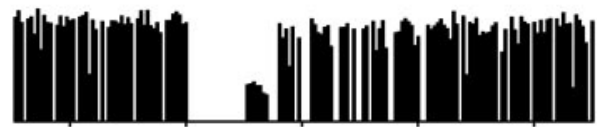

B

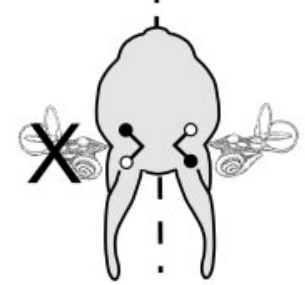

CFRs |||||||| |||। ||| ||||||| | ||||||| || |||। |

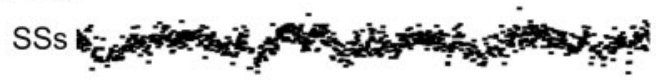

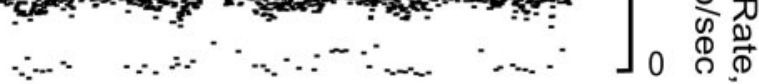

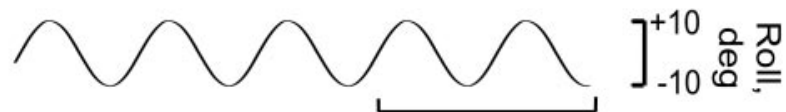

$10 \mathrm{sec}$

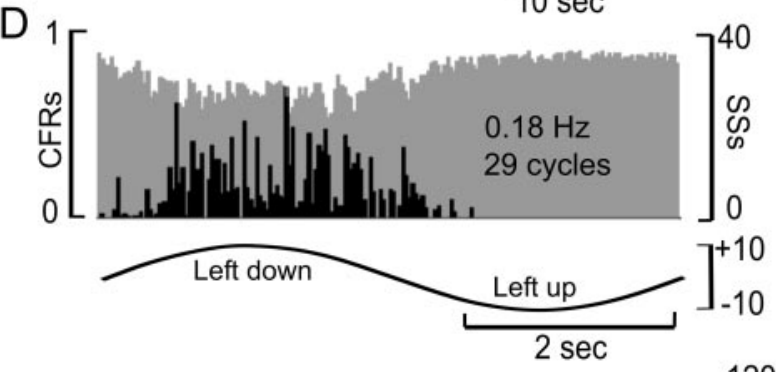

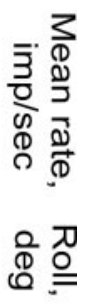

$2 \mathrm{sec}$

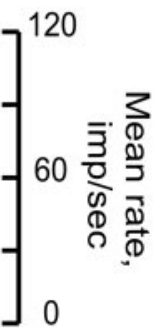

$\mathrm{F}$

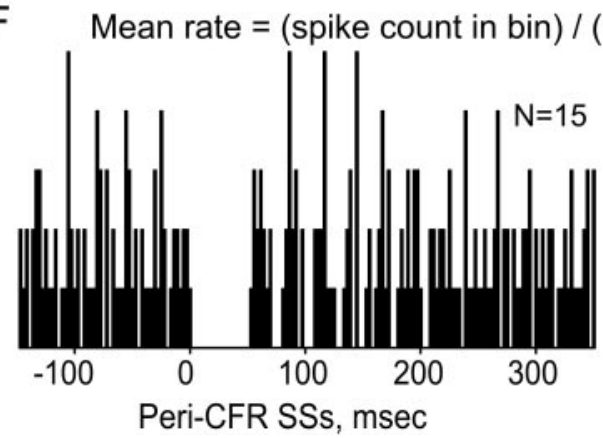

(bin width)(Number of CFR-triggered sweeps)

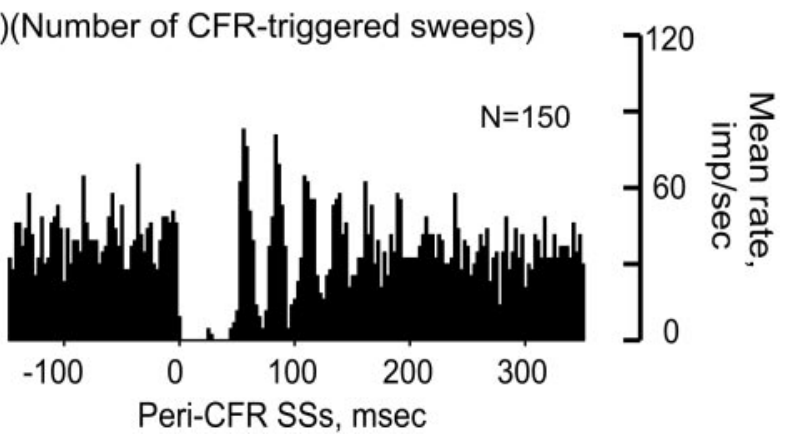

Figure 3. CFRs and SSs are modulated in a Purkinje cell ipsilateral to UL. A, Purkinje cell was located $1.7 \mathrm{~mm}$ lateral to the midline and ipsilateral to the UL. The optimal plane for modulating CFRs was orthogonal to the longitudinal axis. B, CFRs and SSs, modulated by sinusoidal stimulation at $0.2 \mathrm{~Hz}$, are displayed as vertical lines (CFRs) and instantaneous frequency dot displays (SSs). C, Action potentials are illustrated at a faster time base. D, Peristimulus histograms reveal antiphasic modulation of (FRs (black bars) and SSs (gray bars). E, F, Peri-CFR-triggered SS histograms were constructed using two different methods. In $E$, Mean rate $=1 /\left(\sum\right.$ interspike intervals in bin)/(spike count in bin). In $F$, Mean rate $=$ (spike count in bin)/(bin width)(total CFR-triggered sweeps). Both methods sorted the SSs into 180 bins. The histograms in $E$ and F show different totals of CFR-triggered sweeps, 15 and 150. Bin width, 2.78 msec.

each bin and divided by the number of spikes, yielding a mean interspike interval. The reciprocal of this mean interval, frequency, was plotted for each bin in the cycle.

Peri-CFR-triggered histograms were used to examine whether the modulation of SSs was time locked to the occurrence of CFRs. Two methods of constructing peri-CFR-triggered SS histograms were used. The first calculated mean frequency using the reciprocal of the mean SS interspike interval, as described above (Fig. $3 E$ ). The second used the total spike count in each bin divided by the total number of CFR-triggered sweeps multiplied by bin width (Fig. $3 F$ ). The first method preserved information about interspike intervals and provided a lower variability of SS frequency, especially with reduced numbers of CFR-triggered sweeps. Both methods showed that the discharge frequency of SSs was reduced for 50-80 msec after the occurrence of a CFR. Using the first method, the CFR-associated SS pause was mea- sured from the end of the CFR until two successive SS bins had a frequency that was at least $90 \%$ of the pre-CFR frequency (Barmack and Shojaku, 1995). Using this method, the SS pauses evoked in Figure $3 E$ were $78 \mathrm{msec}(n=15)$ and $75 \mathrm{msec}$ $(n=150)$.

The effect of stimulus frequency on CFR-associated antiphasic modulation of SSs was examined in nodular Purkinje cells, ipsilateral to a UL. We asked whether the duration of the SS pause was related to the depth of modulation $\left(D_{\mathrm{m}}\right)$ of CFRs during sinusoidal stimulation. $D_{\mathrm{m}}$ was determined by an iterative search in which the difference in mean CFR frequency in two $90^{\circ}$ quadrants of the sinusoid, separated by $180^{\circ}$, was maximized. Accordingly:

$$
D_{m}=\left[\left(\operatorname{Max}_{90}-\operatorname{Min}_{90}\right) /\left(\operatorname{Max}_{90}+\operatorname{Min}_{90}\right)\right](100 \%) .
$$


A
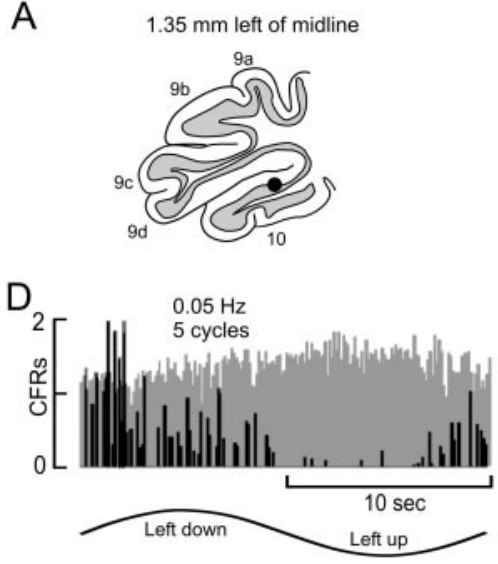

G

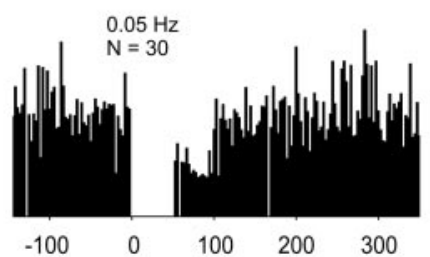

B

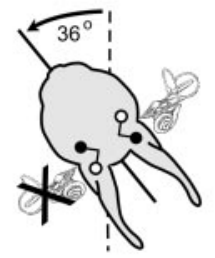

$\mathrm{E}$

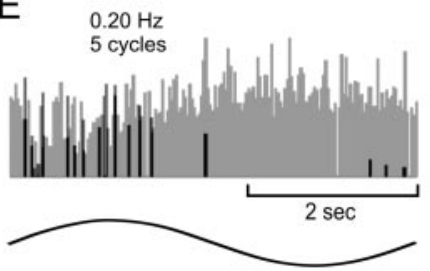

H $\quad 0.20 \mathrm{~Hz}$

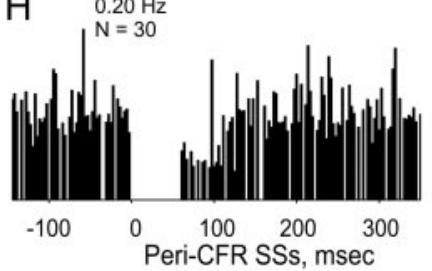

C

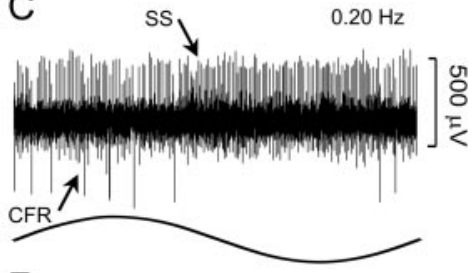

$\mathrm{F}$

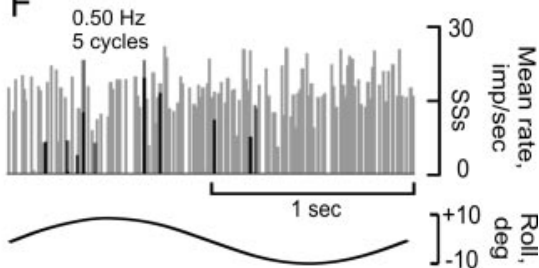

I $\quad 0.50 \mathrm{~Hz}$

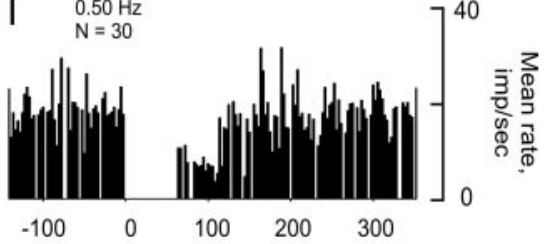

Figure 4. Modulation of CFRs and SSs ipsilateral to UL and frequency-independent CFR-associated SS pause. A, Antiphasically modulated CFRs and SSs were recorded from a nodular Purkinje cell, 1.35 to the left of the midline. $B$, CFRs and SSs were modulated optimally during sinusoidal stimulation in the plane of the intact contralateral posterior semicircular canal. $C$, Modulation of CFRs and SSs was antiphasic. D-F,Peristimulus histograms were constructed at three different stimulus frequencies $(0.05,0.20$, and $0.5 \mathrm{~Hz})$. CFRs are depicted as black, and SSs as gray. G-I, Peri-CFR-triggered SS histograms for each stimulus frequency show that the duration of the CFR-associated pause in SSs was independent of stimulus frequency.

$D_{\mathrm{m}}=100 \%$, when modulated discharge is restricted to one quadrant. $D_{\mathrm{m}}=0 \%$, when CFR frequency is equal in all quadrants.

In a population of 15 Purkinje cells, CFRs and SSs were recorded over a range of stimulus frequencies. We used a $\chi^{2}$ statistic to compare $D_{\mathrm{m}}$ of CFRs and SSs at stimulus frequencies of $0.05,0.20$, and $0.50 \mathrm{~Hz} . D_{\mathrm{m}}$ was independent of stimulus frequency $\left(\chi^{2} ; p>0.08\right.$ for CFRs; $p>0.38$ for SSs). Whereas lower stimulus frequencies evoked greater modulation than did higher stimulus frequencies, the modulation was distributed over a wider segment of each stimulus cycle (Fig. $4 D-F$ ). The CFRassociated pause in SSs remained relatively constant. It was 95 msec at $0.05 \mathrm{~Hz}, 103 \mathrm{msec}$ at $0.20 \mathrm{~Hz}$, and $116 \mathrm{msec}$ at $0.50 \mathrm{~Hz}$ (Fig. $4 G-I$ ). It is possible $D_{\mathrm{m}}$ of vestibularly modulated SSs simply reflected the magnitude of a CFR-associated SS pause.

In some Purkinje cells, the duration of the CFR-associated SS pause was short, but the antiphasic modulation of SSs was large (Fig. 5). Ipsilateral roll-tilt evoked increased discharge of CFRs and decreased discharge of SSs over a range of stimulus frequencies $(0.01-0.20 \mathrm{~Hz})$ (Fig. $5 C-F)$. The peri-CFR-triggered pause lasted $<10 \mathrm{msec}$, suggesting that the CFR-associated SS pause was not directly coupled to $D_{\mathrm{m}}$ of SSs evoked by vestibular stimulation in this particular Purkinje cell (Fig. 5G-I).

The variable relationship between $D_{\mathrm{m}}$ for SSs and the duration of CFR-associated SS pause may reflect the action of several rather than one climbing fiber acting on cerebellar interneurons organized in a sagittal climbing fiber zone (Fushiki and Barmack, 1997). Modulation of SSs is only indirectly linked to the occurrence of a CFR in the same Purkinje cell. A linear regression analysis of the CFR-associated SS pause and $D_{\mathrm{m}}$ for SSs shows that these two variables are not correlated $(r=0.16 ; p>0.38 ; n=28)$.

\section{Antiphasic discharge of CFRs and SSs in the contralateral} uvula-nodulus after UL

If the left labyrinth were the only source of vestibular primary afferents to the left parasolitary nucleus (Psol) and if the left Psol were the only source of descending vestibular signals to the ipsilateral inferior olive, then a left UL should eliminate descending inputs to the ipsilateral (left) $\beta$-nucleus and dmcc and abolish vestibular climbing fiber signals to the contralateral (right) uvula-nodulus. After a UL, we recorded CFRs in 42 Purkinje cells in the contralateral uvulanodulus. CFRs were sensitive to both sinusoidal and static roll-tilt in 34 of 42 Purkinje cells. CFRs were not modulated by vestibular stimulation in only 8 of 42 Purkinje cells. In 21 of 42 Purkinje cells, both CFRs and SSs were well isolated. In 16 of 21 of these Purkinje cells, CFRs were modulated by vestibular stimulation (Fig. 6). Peri-CFR SS histograms showed SS pauses time locked to the occurrence of CFRs. Although the antiphasic discharge of CFRs and SSs was preserved in contralateral as well as ipsilateral Purkinje cells, the duration of the relative SS pause was reduced contralaterally compared with the ipsilateral pause. In a population of 49 Purkinje cells, the duration of the SS pause was greater in Purkinje cells ipsilateral to the $\mathrm{UL}$ (ipsi, $n=28$, mean pause $=64 \mathrm{msec}$; vs contra, $n=21$, mean pause $=46 \mathrm{msec}$; two-tailed $t$ test; $p<0.05)($ Fig. $6 E, H)$. Again, the CFR-associated SS pause was not correlated with $D_{\mathrm{m}}(r=0.13 ; p>$ $0.55 ; n=21)$.

The persistence of contralateral CFRs implies that the circuit drawn in Figure 1 is incomplete. The ipsilateral vestibular projection through the Psol is not the only source of vestibular signaling to the ipsilateral inferior olive. Modification of this circuitry is considered in Discussion.

\section{Bilateral labyrinthectomy prevents modulation of both CFRs} and SSs

One of the possibilities suggested by the persistence of contralateral CFRs after UL is that extra-vestibular inputs to the inferior olive modulate olivary neurons in the absence of vestibular primary afferents. We tested this possibility by recording from 16 Purkinje cells in the uvula-nodulus of an acutely, bilaterally, labyrinthectomized rabbit. None of the CFRs or SSs was modulated by dynamic or static roll-pitch. 
A

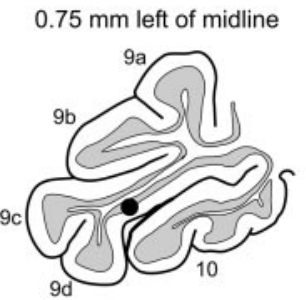

B
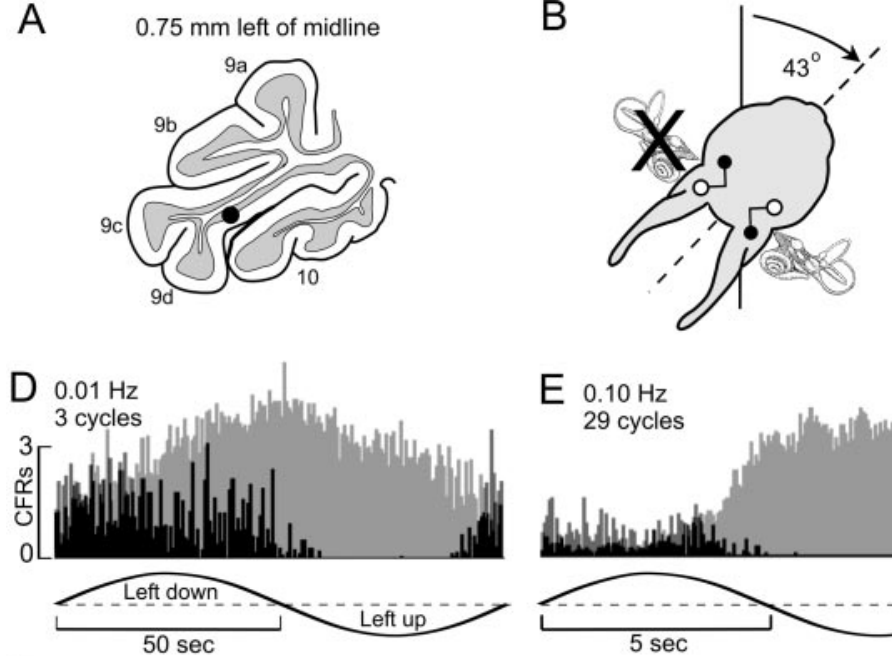

G

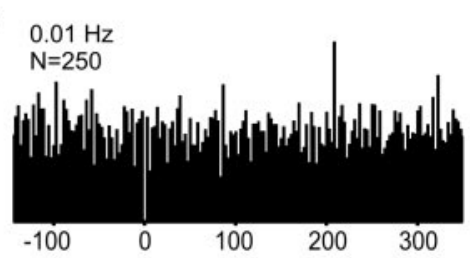

$\mathrm{E} 0.10 \mathrm{~Hz}$ 29 cycles

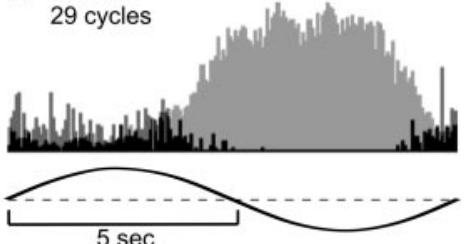

$\mathrm{H} 0.10 \mathrm{~Hz}$ $\mathrm{N}=250$

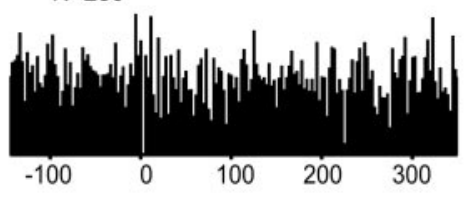

C

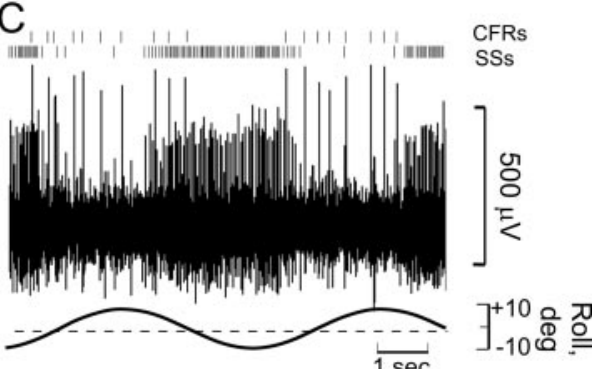

F $\quad \begin{aligned} & 0.20 \mathrm{~Hz} \\ & 7 \text { cycles }\end{aligned}$

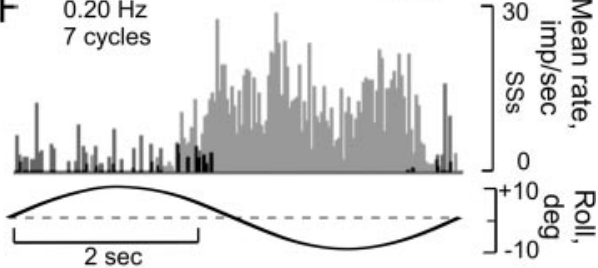

I $0.20 \mathrm{~Hz}$

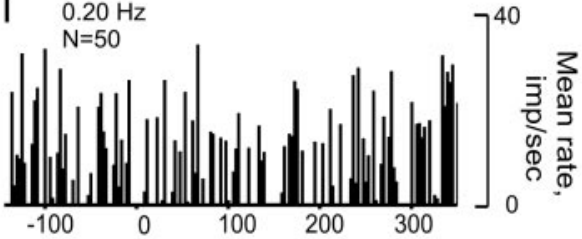

Peri-CFR SSs, msec

Figure 5. Vestibular modulation of CFRs and SSs in Purkinje cell ipsilateral to UL. A, Vestibularly modulated CFRs and SSs were recorded from a Purkinje cell in folia $9 d, 0.75 \mathrm{~mm}$ to the left of the midline after a left UL. B, C, CFRs and SSs were modulated antiphasically during stimulation in an optimal plane, corresponding to the intact right anterior semicircular canal. D-F, Peristimulus histograms for three stimulus frequencies $(0.01,0.10$, and $0.20 \mathrm{~Hz})$, show the antiphasic occurrences of CFRs and SSs. G-I, Peri-CFR SS histograms indicate a CFR-associated pause of $10 \mathrm{msec}$.

A

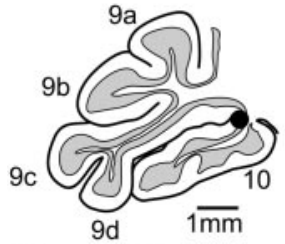

$1.1 \mathrm{~mm}$ right of midline

B

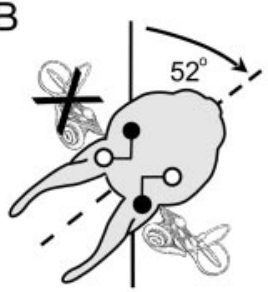

C

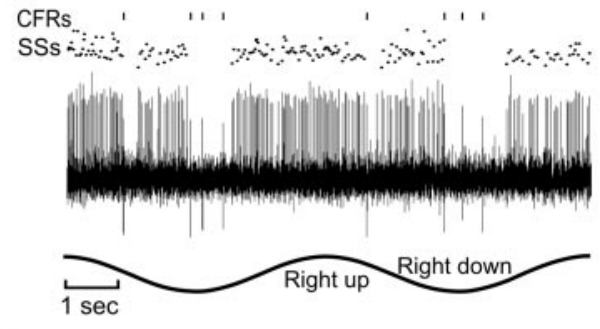

D

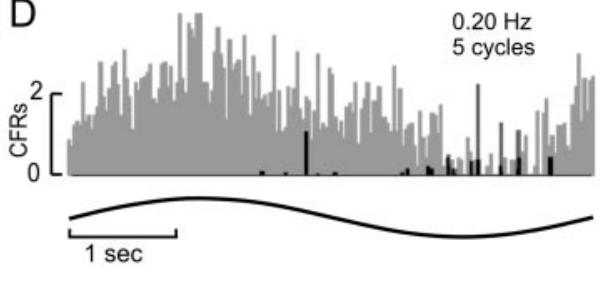

$\mathrm{E}$

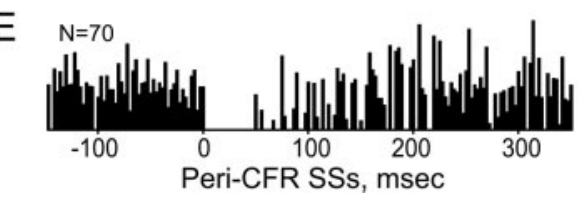

$\mathrm{F}$

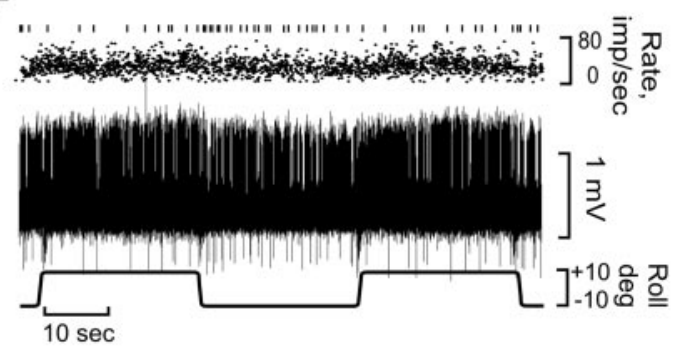

G
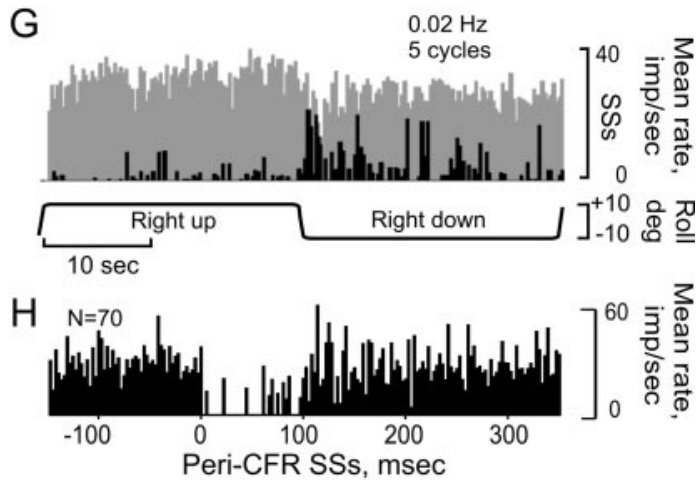

Figure 6. Vestibular modulation of CFRs and SSs in Purkinje cell contralateral to UL. $A$,CFRs and SSs were recorded from a Purkinje cell in the right nodulus after a left UL. $B$, The optimal plane of vestibular stimulation corresponded to the intact right anterior semicircular canal. CFRs increased and SSs decreased when the rabbit was rotated onto its right side during sinusoidal $(C, D)$ or static $(F, G)$ roll-tilt. Peri-CFR-triggered SS histograms recorded during sinusoidal $(E)$ and static roll-tilt $(H)$ vestibular stimulation show a SS pause, lasting $\sim 125$ and 111 msec, respectively.

Quantitative differences in CFRs-SSs in ipsilateral and contralateral uvula-nodulus after UL

$D_{\mathrm{m}}$ and phase angle were plotted in polar coordinates for CFRs and SSs ipsilateral and contralateral to the UL (Fig. $\left.7 A_{1,2}\right) . D_{\mathrm{m}}$ decreased with increasing spontaneous activity. Phase was mea- sured as the peak increase in discharge relative to head position. A response with a phase $=0^{\circ}$ indicates a maximum $D_{\mathrm{m}}$ at ipsilateral side-down position.

The resultant vectors for CFRs in the ipsilateral and contralateral uvula-nodulus were $55 \%$ at $1^{\circ}$ and $69 \%$ at $350^{\circ}$, respectively. 
$\mathrm{A}_{1}$

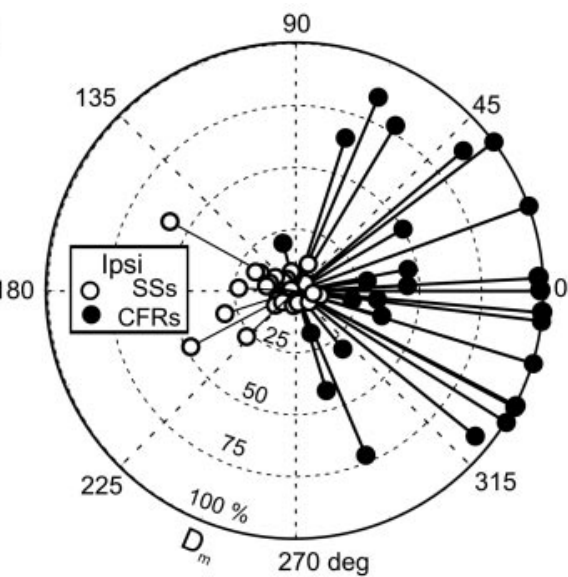

$\mathrm{B}_{1}$

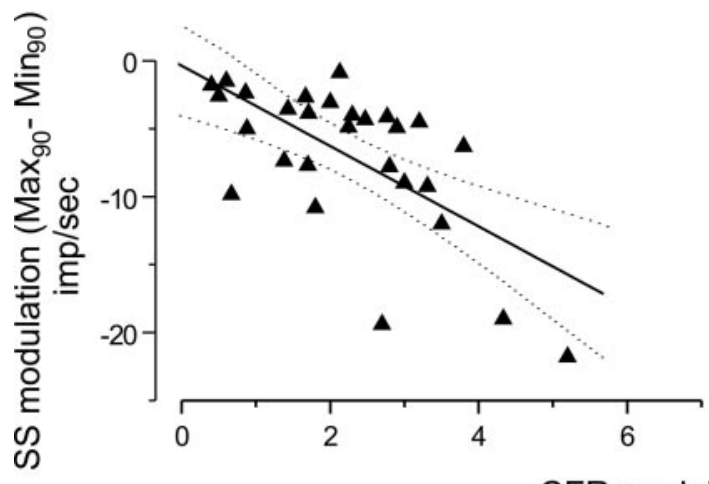

A 2

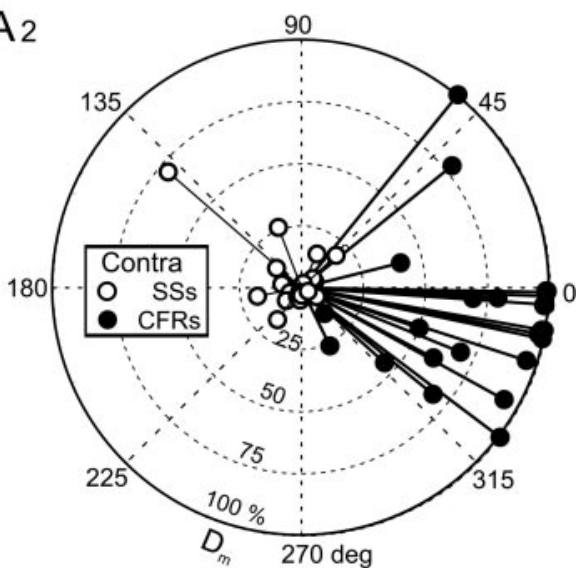

B2
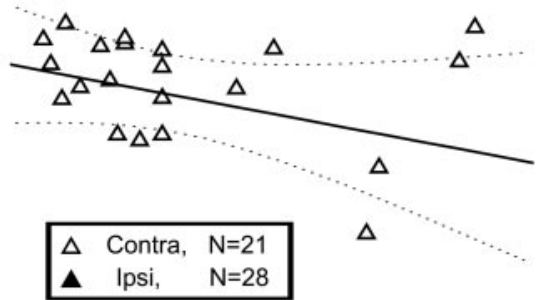

$\Delta$

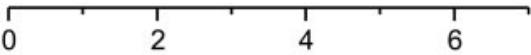

CFR modulation $\left(\operatorname{Max}_{90}-\operatorname{Min}_{90}\right)$, imp/sec

Figure 7. UL reduces the depth of modulation of SSs associated with CFRs in the contralateral uvula-nodulus. The phase and $D_{\mathrm{m}}$ of CFRs and SSs are plotted in polar coordinates for 28 Purkinje cells in the ipsilateral $\left(A_{1}\right)$ and 21 Purkinje cells in the contralateral $\left(A_{2}\right)$ uvula-nodulus after a left UL. Phase was measured relative to ipsilateral side-down head position. Vestibular stimulation was in the optimal plane $(0.1-0.2 \mathrm{~Hz}) . B_{1,2}$, Peak SS modulation was plotted against peak CFR modulation. The slope of this function was reduced in Purkinje cells recorded in the contralateral (right) uvula-nodulus. The dotted lines indicate the 95\% confidence intervals for each fitted regression line. The slope of the regression line fitting the data for Purkinje cells ipsilateral to the UL was statistically greater than that for data from contralateral Purkinje cells.

The resultant $D_{\mathrm{m}}$ and phase for SSs were $8 \%$ at $181^{\circ}$ and $6 \%$ at $141^{\circ}$ (Fig. $7 A_{1,2}$ ). Differences between CFRs and SSs for the two sides were tested for statistical significance using Batschelet's parametric two-sample second-order analysis of angles (Zar, 1984). The resultant vectors for CFRs and SSs recorded from Purkinje cells ipsilateral to the UL were not different than those recorded contralaterally (two-tailed $F$ test: CFRs, $p>0.50$; SSs, $p>0.40 ; n=49)$.

Although the resultant vectors for CFRs and SSs did not differ, a different picture emerged when the absolute modulation depth, $\bar{D}_{\mathrm{m}}=\operatorname{Max}_{90}-\operatorname{Min}_{90}$, of CFRs and SSs was compared for the two sides (Fig. $7 B_{1,2}$ ). $\bar{D}_{\mathrm{m}}$ for CFRs was associated with greater $\bar{D}_{\mathrm{m}}$ in SSs in ipsilateral Purkinje cells compared with contralateral Purkinje cells. The reduced slope of $\bar{D}_{\mathrm{m}}$ for CFRs plotted against $\bar{D}_{\mathrm{m}}$ for SSs for contralateral Purkinje cells was significant (analysis of covariance; $p<0.04 ; n=21$ ). In summary, vigorous modulation of SSs persisted ipsilateral to the UL despite the removal of all ipsilateral vestibular primary afferent mossy fibers. The reduced slope of $\bar{D}_{\mathrm{m}}$ for CFRs versus $\bar{D}_{\mathrm{m}}$ for SSs occurred in the contralateral UL, where the vestibular primary afferent projection remained intact. The slope of $\bar{D}_{\mathrm{m}}$ for CFRs versus $\bar{D}_{\mathrm{m}}$ for SSs in Purkinje cells ipsilateral to the UL was not statistically different from that derived from Purkinje cells recorded from rabbits with intact labyrinths (analysis of covariance; $p>0.90 ; n=29$ ).
Microlesions of $\boldsymbol{\beta}$-nucleus reduce modulated CFRs and SSs in contralateral uvula-nodulus

Although UL failed to eliminate vestibularly modulated CFRs in the contralateral uvula-nodulus, it reduced the CFR-associated modulation of SSs. This suggests two possibilities: (1) the descending vestibular pathway from the parasolitary nucleus to the $\beta$-nucleus and dmcc conveys bilateral vestibular information, or (2) an additional descending vestibular pathway influences the discharge of inferior olivary neurons. If either of these possibilities were correct, vestibular information would still converge on the $\beta$-nucleus and dmcc before being relayed to the contralateral uvula-nodulus. Therefore, we attempted to disrupt descending vestibular afferents at their site of termination in the caudal $\beta$-nucleus rather than at their origin (Barmack et al., 1998).

The uvula-nodulus is divided into sagittal zones defined by the optimal planes of CFRs (Fig. 2). This functional division between CFRs driven by vestibular stimulation in the plane of the ipsilateral posterior and anterior semicircular canals is also represented in the rostral-caudal axis of the $\beta$-nucleus. Olivary neurons in the rostral $\beta$-nucleus have optimal planes corresponding to the plane of the ipsilateral posterior semicircular canal. Neurons in the caudal $\beta$-nucleus have optimal planes corresponding to the plane of the ipsilateral anterior semicircular canal (Fig. $8 B$, open circles) (Barmack et al., 1993b). Caudal $\beta$-nucleus neurons project to a medial zone in the contralateral uvula-nodulus. Ros- 
A
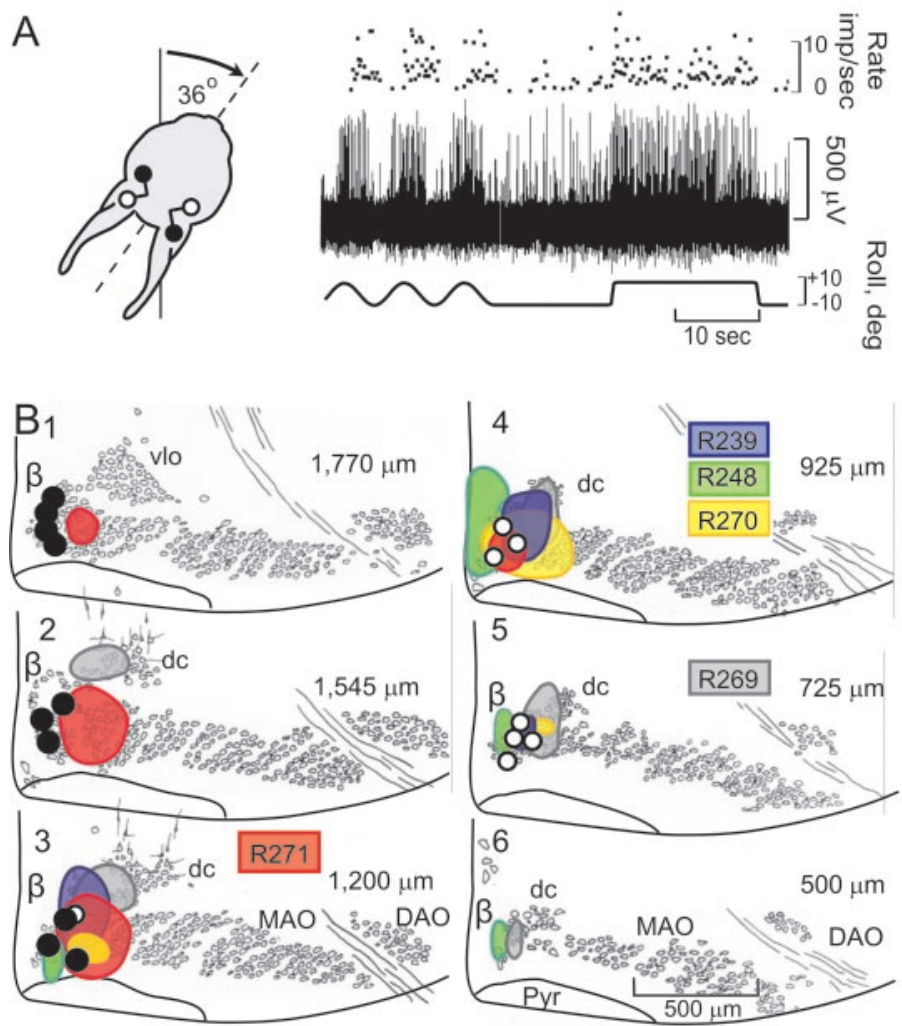

$\mathrm{C}_{1}$

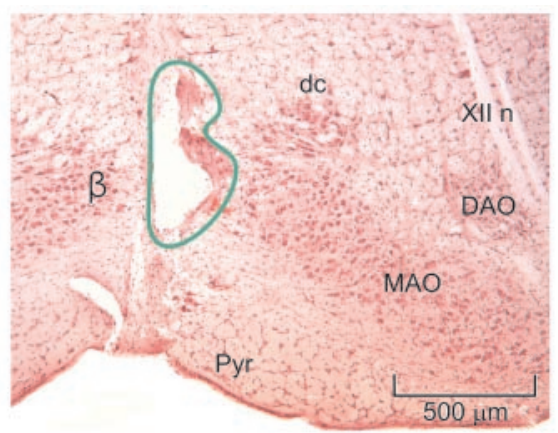

$\mathrm{C}_{2}$

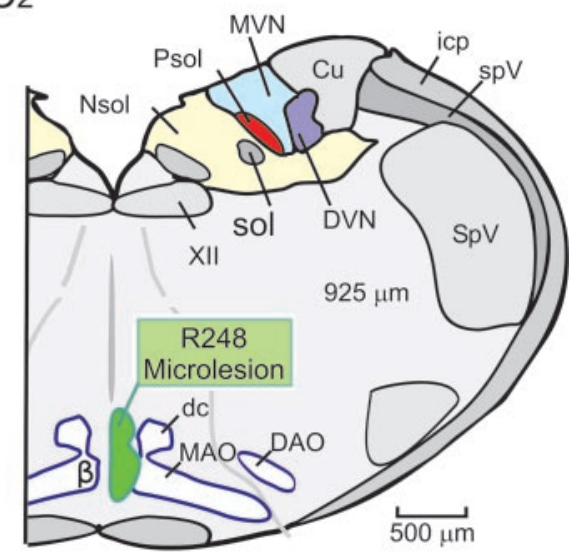

Figure 8. Localization of microlesions of caudal $\beta$-nucleus of inferior olive. Electrolytic microlesions, made in the caudal right $\beta$-nucleus caused reduced modulation of CFRs and SSs recorded in the contralateral uvula-nodulus. $A$, Vestibularly modulated responses of a neuron recorded in the right caudal $\beta$-nucleus were used to guide the placement of the microlesion. The optimal plane corresponded to the right anterior semicircular canal. $B$, Microlesions for five rabbits are illustrated in six transverse sections listed in rostral to caudal order. The distance from the caudal pole of the inferior olive to each section is indicated by the number in upper right corner. The size and location of microlesions in the caudal $\beta$-nucleus are indicated with different colors. Each of five rabbits is identified by number at the level of the transverse section for which its microlesion was largest: R239, blue; R248, green; R269, gray; R270, yellow; R271, red. The locations of 18 $\beta$-nucleus neurons, characterized by their optimal planes, are also indicated. Ten of these neurons (filled circles) had optimal planes aligned with the ipsilateral posterior semicircular canal. Eight neurons (open circles) had optimal planes aligned with the ipsilateral anterior semicircular canal. Neurons with optimal planes aligned with the ipsilateral posterior semicircular canal were located rostral to the section at $925 \mu \mathrm{m}$. Those with optimal planes aligned with the ipsilateral anterior semicircular canal were located caudal to the section at $1200 \mu \mathrm{m}$. $C_{1}$, Photomicrograph of a transverse section, stained with neutral red, shows the maximal extent of the microlesion (R248) made in the right caudal $\beta$-nucleus. $C_{2}$, The, microlesion is illustrated schematically at a level $925 \mu \mathrm{m}$ rostral to the caudal pole of the inferior olive. $\beta, \beta$-Nucleus; Cu, external cuneate nucleus; DA0, dorsal accessory olive; DVN, descending vestibular nucleus; dc, dorsal cap of Kooy; icp, inferior cerebellar peduncle; MA0, medial accessory olive; MVN, medial vestibular nucleus; Nsol, nucleus solitarius; Psol, parasolitary nucleus; Pyr, pyramidal tract; sol, tractus solitarius; SpV, spinal trigeminal nucleus; spV, spinal trigeminal tract; vlo, ventrolateral outgrowth; X, dorsal motor nucleus of the vagus; XII, hypoglossal nucleus; XII n, hypoglossal nerve.

tral $\beta$-nucleus neurons project to a lateral zone in the contralateral uvula-nodulus (Fig. 8 B, filled circles) (Sato and Barmack, 1985). In five rabbits, we identified the caudal half of the $\beta$-nucleus by recording from single olivary neurons during vestibular stimulation (Fig. 8A). Microlesions (10-25 $\mu \mathrm{A}, 30 \mathrm{sec}$; electrode negative) were made at physiologically identified locations. These microlesions destroyed $30-70 \%$ of the caudal $\beta$-nucleus. With one exception, R271, the microlesions minimally invaded the rostral $\beta$-nucleus (Fig. $8 B, C$ ).

By restricting the microlesions to the caudal half of the $\beta$-nucleus, the region containing cells responsive to vestibular stimulation in the plane of the ipsilateral anterior semicircular canal, we could use activity in the ipsilateral lateral and contralateral medial zones as experimental controls. After the microlesion, four recording tracks were made alternately in the ipsilateral and contralateral uvula-nodulus. At the conclusion of each penetration, several marking lesions ( $8 \mu \mathrm{A}, 30 \mathrm{sec}$; electrode negative) were made at depths corresponding to recorded Purkinje cells. These were recovered histologically and plotted on a twodimensional map of the uvula-nodulus (Fig. 9A). The left half of each symbol characterizes the discharge of the CFR. The right half characterizes the SS.
The modulation of CFRs and SSs in the medial zone of the contralateral (left) uvula-nodulus was reduced after a microlesion of the right caudal $\beta$-nucleus. In a sample of 38 Purkinje cells, 6 of 38 had modulated CFRs, 8 of 38 had unmodulated CFRs, and 24 of 38 had no detectable CFRs. Of the 14 Purkinje cells with CFRs, 4 of 14 had weakly driven SSs. Of the 24 Purkinje cells without CFRs, 3 of 24 had SSs modulated in phase with right side-down rotation. Two of 24 had SSs modulated in phase with left side-down rotation.

The $D_{\mathrm{m}}$ of CFRs and SSs in the medial zone of the ipsilateral (right) uvula-nodulus was normal in all respects. In a sample of 19 Purkinje cells, 17 of 19 had modulated CFRs and 2 of 19 had no detectable SSs.

A quantitative comparison of the CFRs and SSs from the contralateral and ipsilateral medial zones was made by a vectorial representation of the data (Fig. 9B). The mean ipsilateral CFR vector exceeded the contralateral CFR vector $\left(\right.$ Ipsi- $D_{\mathrm{m}}=43.9 \%$, phase $=47.6^{\circ}$ vs Contra $-D_{\mathrm{m}}=7.8 \%$, phase $\left.=20.3^{\circ}\right)$. Differences between CFRs and SSs for the two sides were tested for statistical significance using Batschelet's parametric two-sample secondorder analysis of angles (Zar, 1984). The resultant vector for ipsilateral CFRs exceeded the resultant vector for contralateral CFRs 
(one-tailed $F$ test; $p<0.0005$ ). The resultant vector for ipsilateral SSs exceeded the resultant vector for contralateral SSs (Ipsi- $D_{\mathrm{m}}=14.4 \%$, phase $=200.9^{\circ}$ vs Contra- $D_{\mathrm{m}}=0.9 \%$, phase $=244^{\circ}$; onetailed $F$ test; $p<0.005$ ) (Fig. $9 B$ ).

Differences between CFR and SS resultant vectors were reduced when a comparison was made for all ipsilateral versus all contralateral Purkinje cells. Nonetheless, ipsilateral CFR and SS resultant vectors exceeded the contralateral resultant vectors. For CFRs, Ipsi- $D_{\mathrm{m}}=37.3 \%$, phase $=44.8^{\circ}$ versus Contra- $D_{\mathrm{m}}=16.6 \%$, phase $=$ $27.5^{\circ}$; one-tailed $F$ test, $p<0.002$. For SSs, Ipsi- $D_{\mathrm{m}}=12.6 \%$, phase $=206.3^{\circ}$ versus Contra- $D_{\mathrm{m}}=2.86 \%$, phase $=202.6^{\circ}$; onetailed $F$ test, $p<0.02$ (Fig. $9 C$ ).

Differences between CFR and SS resultant vectors were also compared for the lateral zones of the ipsilateral and contralateral uvula-nodulus. Although we attempted to restrict the microlesion to the caudal half of the $\beta$-nucleus, the microlesions encroached on the rostral $\beta$-nucleus, where cells have optimal planes corresponding to the ipsilateral posterior and contralateral anterior semicircular canals. There were no significant differences between CFR and SS resultant vectors when the lateral zones were compared. For CFRs, Ipsi- $D_{\mathrm{m}}=25.2 \%$, phase $=56.2^{\circ}$ versus Contra- $D_{\mathrm{m}}=29.6 \%$, phase $=$ $30.2^{\circ}$; one-tailed $F$ test, $p>0.2$. For SSs, Ipsi- $D_{\mathrm{m}}=10.5 \%$, phase $=220.5^{\circ}$ versus Contra- $D_{\mathrm{m}}=6.2 \%$, phase $=194.6^{\circ}$; onetailed $F$ test, $p>0.2$.

Unequivocal identification of Purkinje cells depends on the detection of CFRs. However, microlesions in the $\beta$-nucleus caused a loss of CFRs in most of the cells recorded in the medial zone of the contralateral uvula-nodulus. Cells without CFRs were classified as Purkinje cells if two conditions were fulfilled: (1) the marking microlesions of these putative Purkinje cells were localized to the Purkinje cell layer, and (2) their recorded depth corresponded to a region of high background activity, characteristic of the Purkinje cell layer.

\section{Microlesions of $\boldsymbol{\beta}$-nucleus have nominal effect on spontaneous SSs in contralateral uvula-nodulus}

Large lesions of the inferior olive raise the spontaneous discharge of SSs in Purkinje neurons (Benedetti et al., 1983). If the spontaneous SS discharge rate were raised to saturation, then it could obscure signal processing normally reflected in modulated SS discharge. In the present experiment, microlesions of the $\beta$-nucleus evoked a modest increase in the spontaneous discharge of SSs in Purkinje cells in the medial zone of the contralateral uvula-nodulus. Contralateral, medial zone Purkinje cells had a spontaneous SS discharge rate $=33.4 \mathrm{imp} / \mathrm{sec}$. Purkinje cells in the ipsilateral medial zone had a spontaneous SS discharge rate = $30.6 \mathrm{imp} / \mathrm{sec}$. This slight elevation in SS frequency in Purkinje
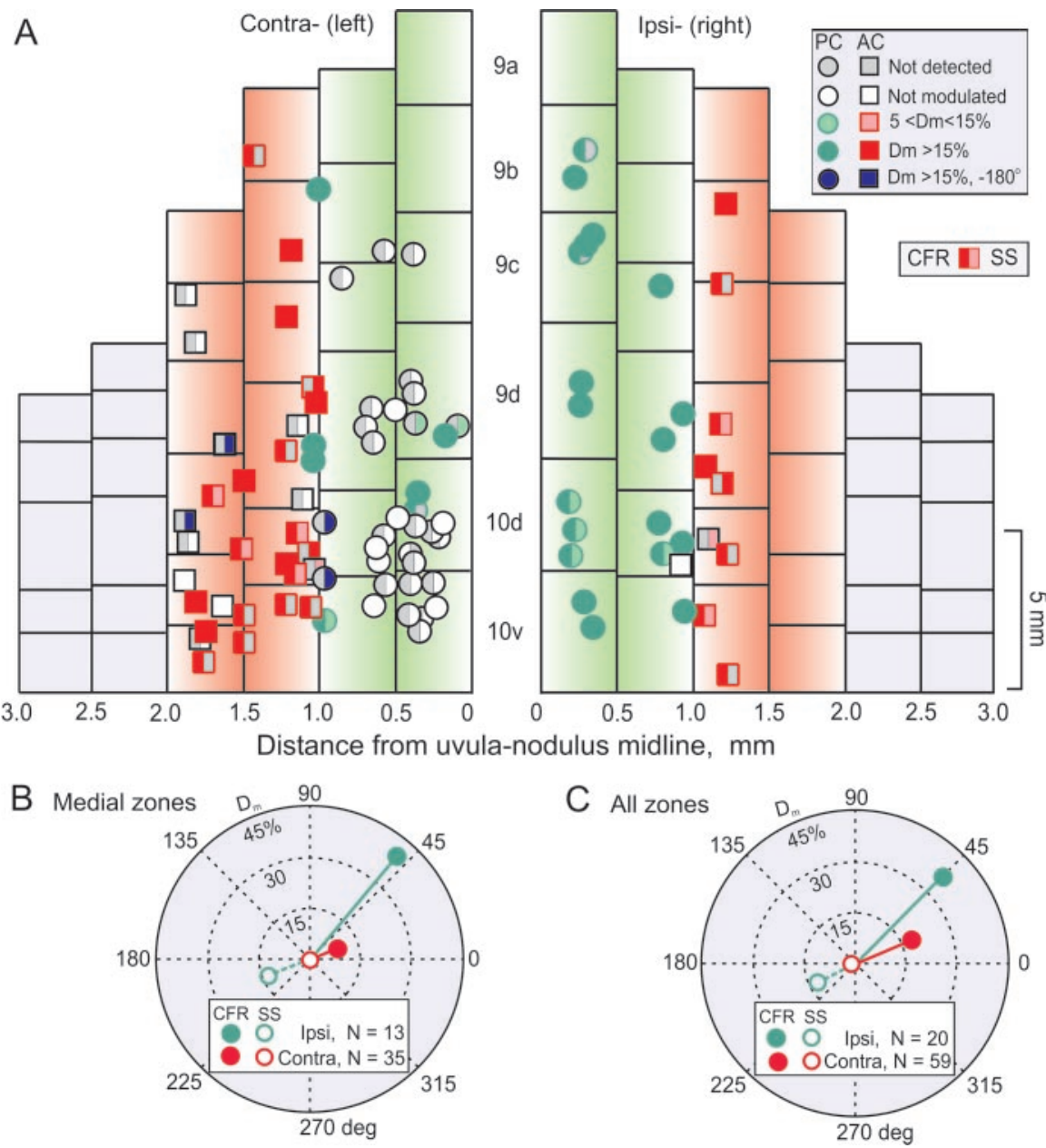

Figure 9. Microlesions of the caudal right $\beta$-nucleus reduce the depth of modulation of contralateral CFRs and SSs. A, Optimal planes for CFRs and depth of modulation for CFRs and SSs were measured in Purkinje cells in uvula-nodulus after microlesions 作 in nodulus after microlesions of the right $\beta$-nucleus. $C$, Polar plot compares $D_{\mathrm{m}}$ for all CFRs and SSs recorded in the ipsilateral and contralateral uvula-nodulus after microlesions of the right $\beta$-nucleus. The vector representing $D_{\mathrm{m}}$ for contralateral $S S \sin$ both $B$ and $C$ was reduced relative to that for ipsilateral SSS.

cells in the contralateral medial zone was not significant (onetailed $t$ test; $p>0.60$ ). Therefore, the loss of SS modulation after olivary microlesions cannot be attributed to an abnormally elevated discharge rate.

\section{Discussion}

Vestibular primary afferent mossy fibers do not modulate SSs in nodular Purkinje cells

Modulation of vestibular primary afferent mossy fibers cannot account for the observed modulated discharge of SSs in rabbits with either intact or damaged labyrinths. In normal rabbits, primary vestibular afferent mossy fiber terminals discharge in phase with ipsilateral side-down rotation (Barmack and Shojaku, 1995). However, SSs discharge out of phase with ipsilateral sidedown rotation. If this out of phase modulation of SSs were caused by the action of ipsilateral vestibular primary afferent mossy fibers, a sign inversion would be required. This raises the possibil- 
ity that either primary vestibular afferents are themselves inhibitory or an inhibitory synapse is interposed between the mossy fiber glomerular synapse on granule cells or between the parallel fiber synapse on Purkinje cells.

The possibility of such a sign inversion at the level of vestibular primary afferents is consistent with the observation that $12 \%$ of vestibular primary afferents express both glutamate and glycine (Reichenberger and Dieringer, 1994). If these glycinergiccontaining primary afferents were inhibitory, they could account for the observed antiphasic modulation of CFRs and SSs in normal rabbits. However, this explanation would ignore the influence of the $88 \%$ of vestibular primary afferents that release glutamate exclusively at the glomerular synapse. Glutamatergic mossy fibers activate kainate and metabotropic glutamate receptors (Raymond et al., 1984; Wisden and Seeburg, 1993; Yamanaka et al., 1997; Smith et al., 1999). Even if glycinecontaining vestibular primary afferents were inhibitory, resulting in antiphasic modulation of CFRs and SSs in normal rabbits, they could not account for the persistence of the antiphasic modulation after a UL.

GABA is released by Golgi cell axon terminals at the glomerulus (Hámori and Takács, 1989). It binds to $\mathrm{GABA}_{\mathrm{A}}$ receptors on the granule cell dendrite (Rossi and Hamann, 1998; Hamann et al., 2002).

Glutamate is released by parallel fibers at synapses on Purkinje cell dendrites, where it stimulates AMPA/kainate and metabotropic glutamate receptors (Somogyi et al., 1986; Kingsbury et al., 1988; Hirano and Hagiwara, 1988; Ottersen et al., 1992; Glaum et al., 1992; Barbour et al., 1994).

The assertion that glutamatergic vestibular primary afferent mossy fibers are not the principal modulatory influence on Purkinje cell SSs rests on two observations. First, modulated SSs are out of phase with the afferent signal of vestibular primary afferents. Second, when vestibular primary afferents are severed, the modulation of SSs persists.

\section{Do secondary vestibular afferents modulate SSs?}

Secondary vestibular afferents could modulate SSs even in the absence of primary vestibular afferents. Unlike vestibular primary afferents, secondary afferents project bilaterally to folia 9d and 10 (Brodal and Hoivik, 1964; Magras and Voogd, 1985; Thunnissen et al., 1989; Epema et al., 1990; Barmack et al., 1992). A UL would not exclude the possibility of modulated vestibular secondary afferents from the contralateral vestibular complex. However, a UL not only acutely depresses activity in the ipsilateral vestibular complex for at least $10 \mathrm{hr}$, it also depresses activity in the contralateral vestibular complex (Precht et al., 1966; Smith and Curthoys, 1988; Ris et al., 1997; Ris and Godaux, 1998). Our experiments typically lasted $6 \mathrm{hr}$ after the UL. It is possible, but unlikely, that residual secondary afferent signals from either the ipsilateral or contralateral vestibular complex contributed to modulated SSs after UL.

Antiphasically modulated CFRs and SSs were observed in cerebellar folia 9a and $9 \mathrm{~b}$ in both normal and UL rabbits. This modulation occurred even though the projection of vestibular primary and secondary afferent mossy fiber afferents is severely reduced compared with the projections to folia 9c, 9d, and 10 (Korte and Mugnaini, 1979; Barmack et al., 1993a; Fushiki and Barmack, 1997).

Vestibular secondary afferents could have a nonlabyrinthine origin, perhaps from visceral receptors. Such afferents might sustain modulated SSs even after a bilateral labyrinthectomy. However, we observed no vestibular modulation of either CFRs or SSs in acutely, bilaterally labyrinthectomized rabbits. Similarly, modulated activity in vestibular secondary neurons is absent in acutely, bilaterally labyrinthectomized cats. In chronically, bilaterally labyrinthectomized cats, secondary vestibular neurons can be weakly modulated by vestibular stimulation (static pitch). This modulated activity is only observed several weeks after the operation and in only $27 \%$ of the recorded neurons (Yates et al., 2000).

\section{Specificity of granule cell function}

Posterior, anterior, and horizontal semicircular canal mossy fiber afferents project to the granule cell layer of the ipsilateral nodulus, whereas a majority of saccular afferents project to the ipsilateral uvula (Purcell and Perachio, 2001;Maklad and Fritzsch, 2003). The utricular macula projects to both nodulus and uvula. Interestingly, whereas horizontal semicircular canal primary afferent mossy fibers project to the nodulus, we recorded no horizontal vestibular modulation of SSs, or CFRs, in nodular Purkinje cells in this experiment or in previous experiments (Barmack and Shojaku, 1995; Fushiki and Barmack, 1997). The horizontal semicircular canals are not represented in either the Psol projection to the inferior olive (Barmack et al., 1993b; Fushiki and Barmack, 1997; Barmack and Yakhnitsa, 2000), or in the olivary projection to the uvula-nodulus (Barmack and Shojaku, 1995; Fushiki and Barmack, 1997).

The possible influences of vestibular primary mossy fiber afferents are not restricted to regions of mossy fiber afferent termination. Vestibular primary afferent signals are dispersed bilaterally by parallel fibers ( $4-7 \mathrm{~mm}$ long) across the entire width of a folium (Brand et al., 1976; Mugnaini, 1983; Pichitpornchai et al., 1994). In contrast, climbing fiber projections are arrayed on the surface of the uvula-nodulus in a coordinate system defined by sagittal transfolial zones in which reciprocal pairs of vertical semicircular canals are represented. The polarization vectors of both CFRs and SSs conform to these climbing fiber sagittal zones. Consequently, vestibular primary mossy fiber afferent projections do not account for the topographic specificity of modulated SSs.

The extended length of parallel fibers makes it improbable that the topographic specificity of mossy fiber afferents and granule cell "patches" is preserved in the overlying Purkinje cell layer. This apparent puzzle has prompted a suggestion that topographic specificity is preserved by means of multisynaptic contacts of ascending granule cell axons (Jaeger and Bower, 1994; Gundappa-Sulur et al., 1999). Regardless of the merits of this conjecture, the observed modulation of SSs in the present experiment was $180^{\circ}$ out of phase with the expected discharge evoked by either ascending axons or parallel fibers contacted by ipsilateral vestibular primary afferents.

Each Purkinje cell in a transfolial beam receives a spatially discrete climbing fiber signal representing a single plane of head movement. In contrast, because of the extended length of parallel fibers, each Purkinje cell receives spatially heterogeneous parallel fiber signals representing all possible planes of head movement, encoded by both ipsilateral and contralateral vestibular end organs.

\section{Cerebellar circuitry and SS modulation}

We suggest that the antiphasic modulation of CFRs and SSs can be ascribed the action of cerebellar interneurons in response to climbing fiber modulation. Here, we consider whether there are $a$ priori reasons for supposing that one of the several cerebellar interneurons is more likely to account for the observed antiphasic modulation of CFRs and SSs. 
Golgi cells

Three observations suggest that Golgi cells may be responsible for the SS modulation. First, cerebellar glomeruli are the principal sites of termination of mossy fibers. Each glomerulus consists of as many as 40 granule cell dendrites, a mossy fiber rosette, and an axon terminal from a Golgi inhibitory interneuron (Hámori and Szentágothai, 1966; Eccles et al., 1966b; Fox et al., 1967). Either of the excitatory mossy fiber terminal or the inhibitory Golgi cell axon terminal could, in principle, modulate the activity of granule cells and, in turn, modulate SSs. Second, Golgi cell axonal terminals have extensive ramifications in the granule cell layer. This allows a spatially restricted climbing fiber signal to influence the activity of large numbers of granule cells. Third, Golgi cells are the only cerebellar interneurons onto which climbing fibers synapse (Hámori and Szentágothai, 1966;Desclin, 1976; Hámori and Szentágothai, 1980; Sugihara et al., 1999). This raises the possibility that climbing fiber-evoked Golgi cell activity could influence SS discharge in Purkinje cells by modulating granule cell discharge.

Vestibularly modulated primary afferent signals, conveyed through granule cell-parallel fibers to Golgi cell dendrites, offer an alternative mechanism for antiphasic modulation of CFRs and SSs. If this circuitry were operative, UL-induced loss of vestibular primary afferent signaling would reduce its efficacy. No such change in the antiphasic discharge of CFRs and SSs was observed in the ipsilateral uvula-nodulus after a UL.

\section{Unipolar brush cells}

Other interneurons also could influence the discharge of SSs, including unipolar brush cells (UBCs). UBCs are found in abundance in the uvula-nodulus (Diño et al., 2000). They receive vestibular primary afferent projections and appear to amplify this vestibular signal through synaptic feed-forward excitation of granule cells. Therefore, UBCs should enhance, not reduce, vestibular mossy fiber synaptic signals at granule cells.

\section{Basket cells}

The dendrites of basket cells, like those of Golgi cells, are contacted by parallel fibers. Basket cells could influence the activity of Purkinje cells through their inhibitory action on Purkinje cell bodies. However, basket cells receive no direct synaptic contacts from climbing fibers (Desclin, 1976; Hámori and Szentágothai, 1980).

\section{Stellate cells}

The dendrites of stellate cells, like those of basket and Golgi cells, receive synaptic contacts from parallel fibers. Stellate cell axon terminals end on Purkinje cell dendrites (Eccles et al., 1967). Like basket cells, stellate cells receive no direct synaptic contacts from climbing fibers.

\section{Lugaro cells}

Located in the upper granule cell layer, Lugaro cells could, in principle, contribute to the antiphasic modulation of CFRs and SSs. Lugaro cells receive projections from Purkinje cells and feed back on basket cells in the molecular layer and Golgi cells in the granule cell layer (Palay and Chan-Palay, 1974; Lainé and Axelrad, 1996). Although lacking a climbing fiber input, these cells nevertheless could provide antiphasically modulated signals from one group of Purkinje cells to an adjacent group.

The general hypothesis that an interneuronal substrate causes antiphasic modulation of CFRs and SSs and the specific hypothesis that the Golgi cell is the interneuron most likely to implement this function, remain plausible. Experiments directed at the anal- ysis of specific signal processing of identified cerebellar interneurons should improve our understanding of the contributions of cerebellar interneurons to the genesis of antiphasic behavior of CFRs and SSs.

\section{Alternative vestibular projections to inferior olive}

Vestibularly modulated CFRs persist in the contralateral uvulanodulus after a UL. This observation suggests that the vestibular projection through the parasolitary nucleus (Psol) to the ipsilateral inferior olive is not the only pathway by which vestibular information reaches the $\beta$-nucleus and dmcc (Fig. 1, \#2,\#3). Using retrograde and orthograde traces, we have shown that the Y-group, a collection of small, spindle-shaped cells ventral to the interpositus nucleus, projects to the contralateral $\beta$-nucleus, dmcc, and dorsal cap (Fig. 1, \#6) (our unpublished observations). Y-group neurons receive primary and secondary vestibular afferents (Kevetter and Perachio, 1986; Blazquez et al., 2000) and project to the ipsilateral flocculus-nodulus as well as the contralateral oculomotor complex and inferior olive (De Zeeuw et al., 1994; Wentzel et al., 1995).

Y-group neurons are labeled immunohistochemically by an antibody to aspartate, rather than to GABA (Kumoi et al., 1987). The projection from the Y-group to the inferior olive implies that olivary projection conveys bilateral vestibular information to the cerebellum. UL causes a loss of the descending input to the inferior olive from the ipsilateral Psol. Residual signals from the intact contralateral labyrinth, relayed through the Y-group, are sufficient to modulate CFRs and SSs. Possibly, the projection from the Y-group to the contralateral $\beta$-nucleus is excitatory and acts reciprocally with the inhibitory projection mediated by the ipsilateral Psol.

\section{Modulation of SSs without modulation of CFRs}

Although it is tempting to assume that high-frequency SSs are "caused" by activity conveyed over the mossy fiber-granule cellparallel fiber pathway, this overstates the synaptic weight of mossy fiber afferents, understates the influence of the climbing fiber pathway, and misrepresents the rich varieties of interactions that emerge from the two afferent systems.

If it were possible to sever completely the climbing fiber projection to the cerebellum, then modulation of SSs could not be attributed directly or indirectly to residual olivary activity. CFRs in floccular Purkinje cells have been reversibly inactivated by microinjections (1-10 nl) of lidocaine into the contralateral dorsal cap (Leonard and Simpson, 1986). After inactivation of a subset of dorsal cap neurons, modulation of SSs persisted in a floccular Purkinje cell during horizontal optokinetic and vestibular stimulation. However intriguing, this experiment does not warrant the conclusion that SS modulation is independent of CFR modulation. Rather, it shows that modulation of SSs in a particular Purkinje cell may be independent of the modulation of the climbing fiber that projects to that same Purkinje cell. Horizontal optokinetic and vestibular modulation of SSs in a floccular Purkinje cell might be influenced by climbing fibers that project to adjacent Purkinje cells and activate common interneuronal circuitry. Such an interpretation is consistent with the classic observation that SS pauses are induced by electrical stimulation of the inferior olive, even when the electrical stimulus is subthreshold for evoking a CFR in the Purkinje cell from which SSs are recorded (Bloedel and Roberts, 1971).

Modulation of SSs in a nodular Purkinje cell depends on the location of the Purkinje cell within a functional zone. The depth of SS modulation is greater for Purkinje cells located in the center 
of a climbing fiber zone (Fushiki and Barmack, 1997). Conversely, SS modulation is weaker in Purkinje cells located near a zonal border.

\section{Short-term and long-term functions of CFRs}

The low frequency of discharge of CFRs has been rationalized theoretically by ascribing to it "higher order" functions. CFRs have been likened to "phasic motor generators" (Berthoz and Llinás, 1974), "threshold devices" (Murphy et al., 1973), "event detectors" (Rushmer et al., 1976), "error detectors" (Andersson and Armstrong, 1987), "frequency synchronizers" (Llinás and Yarom, 1986), and "gain changers" (Ebner and Bloedel, 1981). Implicit in these views is the assumption that discharge of CFRs is either too low or too intermittent to encode faithfully cerebellar inputs. These conjectures do not apply to CFRs modulated by vestibular and optokinetic stimulation in the nodulus and flocculus. These modes of stimulation are encoded parametrically by CFRs (Simpson and Alley, 1974; Barmack and Hess, 1980; Simpson et al., 1981; Fushiki and Barmack, 1997).

The discharge of CFRs is associated with a reduction of SSs. As discussed previously, this reduction may be caused by Golgi cell inhibition of granule cells or by some other interneuronal mechanism. In the short term, the antiphasic discharge of CFR-evoked antiphasic SS modulation could provide a spatial filter through which CFRs with a high spatial resolution and low bandwidth modulate SSs with a low spatial resolution and high bandwidth.

In the long term, climbing fibers could modulate SSs through the cellular mechanism of long-term depression (LTD) (Ito et al., 1982; Sakurai, 1987; Ito and Karachot, 1989; Crépel and Jaillard, 1991). LTD is characterized by reduced synaptic efficacy of parallel fibers after conjunctive stimulation of parallel and climbing fibers (Narasimhan and Linden, 1996). LTD allows a single climbing fiber to decrease the synaptic influence of a simultaneously active set of parallel fibers. Functionally, a single CFR could change the synaptic weighting of as many as 150,000 granule cells distributed across several functional zones within the cerebellum. LTD may use the topography of CFRs to change the synaptic weighting of parallel fiber inputs with which they are dynamically associated (Ekerot and Jörntell, 2001; Jörntell and Ekerot, 2002).

Climbing fibers not only evoke low-frequency CFRs, but also determine, in part, the topography, polarity, and depth of modulation of higher-frequency SSs. Parallel fibers provide bilateral vestibular information to each Purkinje cell about the status of each end organ. This information is shaped by conjunctive climbing fiber activity.

\section{References}

Andersson G, Armstrong DM (1987) Complex spikes in Purkinje cells in the lateral vermis of the cat cerebellum during locomotion. J Physiol (Lond) 385:107-134.

Barbour B, Keller BU, Llano I, Marty A (1994) Prolonged presence of glutamate during excitatory synaptic transmission to cerebellar Purkinje cells. Neuron 12:1331-1343.

Barmack NH (1996) GABAergic pathways convey vestibular information to the $\beta$ nucleus and dorsomedial cell column of the inferior olive. In: New directions in vestibular research (Highstein SM, Cohen B, BüttnerEnnever J, eds), pp 541-552. New York: New York Academy of Science.

Barmack NH, Hess DT (1980) Multiple-unit activity evoked in dorsal cap of inferior olive of the rabbit by visual stimulation. J Neurophysiol 43:151-164.

Barmack NH, Shojaku H (1995) Vestibular and visual signals evoked in the uvula-nodulus of the rabbit cerebellum by natural stimulation. J Neurophysiol 74:2573-2589.

Barmack NH, Yakhnitsa V (2000) Vestibular signals in the parasolitary nucleus. J Neurophysiol 83:3559-3569.
Barmack NH, Baughman RW, Eckenstein FP, Shojaku H (1992) Secondary vestibular cholinergic projection to the cerebellum of rabbit and rat as revealed by choline acetyltransferase immunohistochemistry, retrograde and orthograde tracers. J Comp Neurol 317:250-270.

Barmack NH, Baughman RW, Errico P, Shojaku H (1993a) Vestibular primary afferent projection to the cerebellum of the rabbit. J Comp Neurol 327:521-534.

Barmack NH, Fagerson M, Fredette BJ, Mugnaini E, Shojaku H (1993b) Activity of neurons in the beta nucleus of the inferior olive of the rabbit evoked by natural vestibular stimulation. Exp Brain Res 94:203-215.

Barmack NH, Fredette BJ, Mugnaini E (1998) Parasolitary nucleus: a source of GABAergic vestibular information to the inferior olive of rat and rabbit. J Comp Neurol 392:352-372.

Bell CC, Grimm RJ (1969) Discharge properties of Purkinje cells recorded on single and double microelectrodes. J Neurophysiol 32:1044-1055.

Benedetti F, Montarolo PF, Strata P, Tempia F (1983) Inferior olive inactivation decreases the excitability of the intracerebellar and lateral vestibular nuclei in the rat. J Physiol (Lond) 340:195-208.

Berthoz A, Llinás R (1974) Afferent neck projection to the cat cerebellar cortex. Exp Brain Res 20:385-401.

Blazquez P, Partsalis A, Gerrits NM, Highstein SM (2000) Input of anterior and posterior semicircular canal interneurons encoding head-velocity to the dorsal Y group of the vestibular nuclei. J Neurophysiol 83:2891-2904.

Bloedel JR, Roberts WJ (1971) Action of climbing fibers in cerebellar cortex of the cat. J Neurophysiol 34:17-31.

Brand S, Dahl AL, Mugnaini E (1976) The length of parallel fibers in the cat cerebellar cortex. An experimental light and electron microscopic study. Exp Brain Res 26:39-58.

Brodal A, Hoivik B (1964) Site and mode of termination of primary vestibulocerebellar fibres in the cat. Arch Ital Biol 102:1-21.

Carpenter MB, Stein BM, Peter P (1972) Primary vestibulocerebellar fibers in the monkey: distribution of fibers arising from distinctive cell groups of the vestibular ganglia. Am J Anat 135:221-250.

Crépel F, Jaillard D (1991) Pairing of pre- and postsynaptic activities in cerebellar Purkinje cells induces long-term changes in synaptic efficacy in vitro. J Physiol (Lond) 432:123-141.

De Zeeuw CI, Gerrits NM, Voogd J, Leonard CS, Simpson JI (1994) The rostral dorsal cap and ventrolateral outgrowth of the rabbit inferior olive receive a GABAergic input from dorsal group $\mathrm{Y}$ and the ventral dentate nucleus. J Comp Neurol 341:420-432.

Desclin JC (1976) Early terminal degeneration of cerebellar climbing fibers after destruction of the inferior olive in the rat. Synaptic relationships in the molecular layer. Anat Embryol (Berl) 149:87-112.

Diño MR, Schuerger RJ, Liu YB, Slater NT, Mugnaini E (2000) Unipolar brush cell: a potential feedforward excitatory interneuron of the cerebellum. Neuroscience 98:625-636.

Ebner TJ, Bloedel JR (1981) Role of climbing fiber afferent input in determining responsiveness of Purkinje cells to mossy fiber inputs. J Neurophysiol 45:962-971.

Eccles JC, Llinás R, Sasaki K (1966a) The excitatory synaptic action of climbing fibers on the Purkinje cells of the cerebellum. J Physiol (Lond) 182:268-296.

Eccles JC, Llinás R, Sasaki K (1966b) The mossy fibre-granule cell relay of the cerebellum and its inhibitory control by Golgi cells. Exp Brain Res 1:82-101.

Eccles JC, Ito M, Szentágothai J (1967) The cerebellum as a neuronal machine. New York: Springer.

Ekerot CF, Jörntell H (2001) Parallel fibre receptive fields of Purkinje cells and interneurons are climbing fibre-specific. Eur J Neurosci 13:1303-1310.

Epema AH, Gerrits NM, Voogd J (1990) Secondary vestibulocerebellar projections to the flocculus and uvulo-nodular lobule of the rabbit: a study using HRP and double fluorescent tracer techniques. Exp Brain Res 80:72-82.

Fox CA, Hillman DE, Siegesmund KA, Dutta CR (1967) The primate cerebellar cortex: a Golgi and electron microscopic study. In: Progress in brain research: the cerebellum, Vol 25 (Fox CA, Snider RS, eds), pp 174-225. New York: Elsevier.

Fushiki H, Barmack NH (1997) Topography and reciprocal activity of cerebellar Purkinje cells in the uvula-nodulus modulated by vestibular stimulation. J Neurophysiol 78:3083-3094.

Glaum SR, Slater NT, Rossi DJ, Miller RJ (1992) Role of metabotropic glutamate (ACPD) receptors at the parallel fiber-Purkinje cell synapse. J Neurophysiol 68:1453-1462. 
Granit R, Phillips CG (1956) Excitatory and inhibitory processes acting upon individual Purkinje cells of the cerebellum in cats. J Physiol (Lond) 133:520-547.

Gundappa-Sulur G, De Schutter E, Bower JM (1999) Ascending granule cell axon: an important component of cerebellar cortical circuitry. J Comp Neurol 408:580-596.

Hamann M, Rossi DJ, Attwell D (2002) Tonic and spillover inhibition of granule cells control information flow through cerebellar cortex. Neuron 33:625-633.

Hámori J, Szentágothai J (1966) Participation of Golgi neuron processes in the cerebellar glomeruli: an electron microscope study. Exp Brain Res 2:35-48.

Hámori J, Szentágothai J (1980) Lack of evidence of synaptic contacts by climbing fiber collaterals to basket and stellate cells in developing rat cerebellar cortex. Brain Res 186:454-457.

Hámori J, Takács J (1989) Two types of GABA-containing axon terminals in cerebellar glomeruli of cat: an immunogold-EM study. Exp Brain Res 74:471-479.

Hirano T, Hagiwara S (1988) Synaptic transmission between rat cerebellar granule and Purkinje cells in dissociated cell culture: effects of excitatoryamino acid transmitter antagonists. Proc Natl Acad Sci USA 85:934-938.

Ito M, Karachot L (1989) Long-term desensitization of quisqualate-specific glutamate receptors in Purkinje cells investigated with wedge recording from rat cerebellar slices. Neurosci Res 7:168-171.

Ito M, Sakurai M, Tongroach P (1982) Climbing fibre induced depression on both mossy fibre responsiveness and glutamate sensitivity of cerebellar Purkinje cells. J Physiol (Lond) 324:113-134.

Jaeger D, Bower JM (1994) Prolonged responses in rat cerebellar Purkinje cells following activation of the granule cell layer: an intracellular in vitro and in vivo investigation. Exp Brain Res 100:200-214.

Jörntell H, Ekerot CF (2002) Reciprocal bidirectional plasticity of parallel fiber receptive fields in cerebellar Purkinje cells and their afferent interneurons. Neuron 34:797-806.

Kaufman GD, Mustari MJ, Miselis RR, Perachio AA (1996) Transneuronal pathways to the vestibulocerebellum. J Comp Neurol 370:501-523.

Kevetter GA, Perachio A (1986) Distribution of vestibular afferents that innervate the sacculus and posterior canal in the gerbil. J Comp Neurol 254:410-424.

Kingsbury A, Gallo V, Balazs R (1988) Stimulus-coupled release of amino acids from cerebellar granule cells in culture. Brain Res 448:46-52.

Korte GE (1979) The brainstem projection of the vestibular nerve in the cat. J Comp Neurol 184:279-292.

Korte G, Mugnaini E (1979) The cerebellar projection of the vestibular nerve in the cat. J Comp Neurol 184:265-278.

Kumoi K, Saito N, Tanaka C (1987) Immunohistochemical localization of $\gamma$-aminobutyric acid-and aspartate-containing neurons in the guinea pig vestibular nuclei. Brain Res 416:22-23.

Lainé J, Axelrad H (1996) Morphology of the Golgi-impregnated Lugaro cell in the rat cerebellar cortex: a reappraisal with a description of its axon. J Comp Neurol 375:618-640.

Leonard CS, Simpson JI (1986) Simple spike modulation of floccular Purkinje cells during reversible blockade of their climbing fiber afferents. In: Adaptive processes in visual and oculomotor systems (Keller E, Zee D, eds), pp 429-434. Oxford: Pergamon.

Leonard CS, Simpson JI, Graf W (1988) Spatial organization of visual messages of the rabbit's cerebellar flocculus. I. Typology of inferior olive neurons of the dorsal cap of Kooy. J Neurophysiol 60:2073-2090.

Llinás RR, Yarom Y (1986) Oscillatory properties of guinea-pig inferior olivary neurones in vitro. J Physiol (Lond) 376:163-182.

Magras IN, Voogd J (1985) Distribution of the secondary vestibular fibers in the cerebellar cortex. Acta Anat 123:51-57.

Maklad A, Fritzsch B (2003) Partial segregation of posterior crista and saccular fibers to the nodulus and uvula of the cerebellum in mice, and its development. Dev Brain Res 140:223-236.

Mugnaini E (1983) The length of cerebellar parallel fibers in chicken and rhesus monkey. J Comp Neurol 220:7-15.

Murphy JT, MacKay WA, Johnson F (1973) Differences between cerebellar mossy and climbing fibre responses to natural stimulation of forelimb muscle proprioceptors. Brain Res 55:263-289.

Narasimhan K, Linden DJ (1996) Defining a minimal computational unit for cerebellar long-term depression. Neuron 17:333-341.
Ottersen OP, Zhang N, Walberg F (1992) Metabolic compartmentation of glutamate and glutamine: morphological evidence obtained by quantitative immunocytochemistry in rat cerebellum. Neuroscience 46:519-534.

Palay SL, Chan-Palay V (1974) Cerebellar cortex: cytology and organization. Heidelberg: Springer.

Pichitpornchai C, Rawson JA, Rees S (1994) Morphology of parallel fibers in the cerebellar cortex of the rat-an experimental light and electronmicroscopic study with biocytin. J Comp Neurol 342:206-220.

Precht W, Shimazu H, Markham CH (1966) A mechanism of central compensation of vestibular function following hemilabyrinthectomy. J Neurophysiol 29:996-1010.

Purcell IM, Perachio AA (2001) Peripheral patterns of terminal innervation of vestibular primary afferent neurons projecting to the vestibulocerebellum in the gerbil. J Comp Neurol 433:48-61.

Raymond J, Nieoullon A, Dememes D, Sans A (1984) Evidence for glutamate as a neurotransmitter in the cat vestibular nerve: radioautographic and biochemical studies. Exp Brain Res 56:523-531.

Reichenberger I, Dieringer N (1994) Size-related colocalization of glycine and glutamate immunoreactivity in frog and rat vestibular afferents. J Comp Neurol 349:603-614.

Ris L, Godaux E (1998) Neuronal activity in the vestibular nuclei after contralateral or bilateral labyrinthectomy in the alert guinea pig. J Neurophysiol 80:2352-2367.

Ris L, Capron B, De Waele C, Vidal P-P, Godaux E (1997) Dissociations between behavioural recovery and restoration of vestibular activity in the unilabyrinthectomized guinea-pig. J Physiol (Lond) 500:509-522.

Rossi DJ, Hamann M (1998) Spillover-mediated transmission at inhibitory synapses promoted by high affinity $\alpha 6$ subunit GABA(A) receptors and glomerular geometry. Neuron 20:783-795.

Rushmer DS, Roberts WJ, Augter GK (1976) Climbing fiber responses of cerebellar Purkinje cells to passive movement of the cat forepaw. Brain Res 106:1-20.

Sakurai M (1987) Synaptic modification of parallel fibre-Purkinje cell transmission in in vitro guinea-pig cerebellar slices. J Physiol (Lond) 394:463-480.

Sato Y, Barmack NH (1985) Zonal organization of the olivocerebellar projection to the uvula in rabbits. Brain Res 359:281-291.

Simpson JI, Alley KE (1974) Visual climbing fiber input to rabbit vestibulocerebellum: a source of direction-specific information. Brain Res 82:302-308.

Simpson JI, Graf W, Leonard C (1981) The coordinate system of visual climbing fibers to the flocculus. In: Developments in neuroscience: progress in oculomotor research, Vol 12 (Fuchs AF, Becker W, eds), pp 475-484. North Holland: Elsevier.

Smith PF, Curthoys IS (1988) Neuronal activity in the ipsilateral medial vestibular nucleus of the guinea pig following unilateral labyrinthectomy. Brain Res 444:308-319.

Smith TC, Wang LY, Howe JR (1999) Distinct kainate receptor phenotypes in immature and mature mouse cerebellar granule cells. J Physiol 517:51-58.

Somogyi P, Halasy K, Somogyi J, Storm-Mathisen J, Ottersen OP (1986) Quantification of immunogold labelling reveals enrichment of glutamate in mossy and parallel fiber terminals in cat cerebellum. Neuroscience 19:1045-1050.

Sugihara I, Wu H, Shinoda Y (1999) Morphology of single olivocerebellar axons labeled with biotinylated dextran amine in the rat. J Comp Neurol 414:131-148.

Thunnissen IE, Epema AH, Gerrits NM (1989) Secondary vestibulocerebellar mossy fiber projection to the caudal vermis in the rabbit. J Comp Neurol 290:262-277.

Wentzel PR, Wylie DR, Ruigrok TJ, De Zeeuw CI (1995) Olivary projecting neurons in the nucleus prepositus hypoglossi, group y and ventral dentate nucleus do not project to the oculomotor complex in the rabbit and the rat. Neurosci Lett 190:45-48.

Wisden W, Seeburg PH (1993) A complex mosaic of high-affinity kainate receptors in rat brain. J Neurosci 13:3582-3598.

Yamanaka T, Sasa M, Matsunaga T (1997) Glutamate as a primary afferent neurotransmitter in the medial vestibular nucleus as detected by in vivo microdialysis. Brain Res 762:243-246.

Yates BJ, Jian BJ, Cotter LA, Cass SP (2000) Responses of vestibular nucleus neurons to tilt following chronic bilateral removal of vestibular inputs. Exp Brain Res 130:151-158.

Zar JH (1984) Biostatistical analysis. Englewood Cliffs, NJ: Prentice-Hall. 